(C) Dereito Vol.28, n01:45-84 (Xaneiro-Xuño, 2019) • ISSN 1132-9947

\title{
LOS INTERESES PROTEGIDOS POR MEDIO DE LAS ACCIONES COLECTIVAS
}

The interests protected through collective actions

DOI: http://dx.doi.org/10.15304/dereito.28.1.4116

María Jesús SAnde Mayo

Doctora en Derecho

Centro de Estudios Garigues

mariajesus.sandemayo@gmail.com

\section{Resumen}

Una de las grandes dificultades que presenta el estudio de las acciones colectivas reside en la confusión existente en el plano terminológico. Y es que las dos especies de intereses protegidas por medio de este instrumento procesal no han sido delimitadas con claridad ni por la doctrina ni tampoco por la jurisprudencia. A su vez, la Ley de Enjuiciamiento Civil utiliza la expresión "intereses colectivos y difusos" para referirse tanto a los intereses supraindividuales como a los intereses individuales homogéneos, lo cual resulta inadecuado y aduce todavía mayor confusión. A la vista de las dificultades que genera en la práctica la ausencia de claridad a este respecto, nuestro propósito en las líneas que siguen es el de arrojar luz, en la medida de lo posible, en torno a la delimitación de los intereses que por medio de las acciones colectivas se protegen.

Palabras clave: Intereses supraindividuales; Intereses individuales homogéneos; Intereses de incidencia social; Acciones colectivas.

\section{Abstract}

One of the great difficulties that presents the study of collective actions lies in the confusion at the terminological level. The two species of interests protected by this procedural instrument have not been clearly delineated either by doctrine or by jurisprudence. At the same time, the Civil Procedure Act uses the expression "collective and diffuse interests" to refer the two categories of interests protected by collective actions, which is inappropriate and argues yet more confusion. In view of the difficulties generated in practice by the lack of clarity in this regard, our purpose in the following lines is to shed light, as far as possible, on the delimitation of interests that are protected by collective action.

Keywords: Supraindividual interests; Homogeneous individual interests; Interests of social incidence; Collective actions.

\section{SUMARIO}

1.- INTRODUCCIÓN. 2.- EL PROBLEMA TERMINOLÓGICO. 3.- LOS INTERESES SUPRAINDIVIDUALES. 3.1.- Naturaleza jurídica. 3.1.1.- Suma de intereses individuales vs. categoría autónoma. 3.1.2.- Derechos 
subjetivos e intereses legítimos. 3.1.3. Naturaleza pública, privada o tertium genus. 3.2.- Intereses «colectivos» y «difusos». 4.- LOS INTERESES INDIVIDUALES HOMOGÉNEOS. 4.1.- Naturaleza jurídica. 4.2.Presupuestos para su tutela colectiva. 4.3.- Intereses individuales homogéneos susceptibles de tutela colectiva. 5.- LOS INTERESES DE INCIDENCIA SOCIAL DE LOS CONSUMIDORES EN LA LEC. 6.CONCLUSIONES. 7.- BIBLIOGRAFÍA.

\section{INTRODUCCIÓN}

El estudio de las acciones colectivas y, como paso previo, el de las situaciones jurídicas de ventaja que a su través pretenden protegerse -esto es, los intereses supraindividuales e individuales homogéneosgenera en quien se acerca a ellas por vez primera, una situación de inquietud e inseguridad, motivada en gran medida por el anarquismo conceptual y el uso asistemático de las expresiones y conceptos. Y es que al tiempo que se emplea un mismo término para hacer referencia a realidades diversas, no siempre se utiliza el mismo vocablo para aludir a la misma situación ${ }^{1}$.

A su vez, el estudio de los intereses cuya relevancia trasciende la meramente individual, no ha sido abordado únicamente desde la disciplina del Derecho Procesal, de ahí que las interferencias entre las distintas ramas del ordenamiento que se han dedicado a su estudio -fundamentalmente las provenientes del Derecho Administrativo y Laboral- hayan repercutido negativamente en la construcción de conceptos estables en el marco del Derecho Procesal.

Así, de la confusión que históricamente ha reinado en torno al estudio de las nuevas situaciones jurídicas objeto de protección, se eleva el primero $y$, al tiempo, uno de los más importantes hitos en el estudio de las «acciones colectivas», cual es el terminológico. La ausencia de nitidez a este respecto no sólo dificulta el estudio de las situaciones de ventaja de incidencia social y a la postre del instrumento procesal dedicado a su defensa, sino que también revela la inconsistencia del sustrato de fondo sobre el que se asientan las argumentaciones doctrinales formuladas a su respecto.

Ad maiorem, la LEC tampoco ha supuesto grandes avances en lo relativo a la clarificación de dichos conceptos, pues emplea la expresión «intereses colectivos y difusos» para referirse tanto a los intereses supraindividuales como a los individuales homogéneos, acarreando este tratamiento unitario confusión en la práctica. Ante la ausencia de definiciones por parte de la Ley procesal civil en torno a las diferentes categorías de intereses nacidos de la sociedad del consumo en masa, la delimitación de cada una de ellas se revela decisiva para poder identificar qué intereses o derechos se encuentran en el sustrato de cada una de las especialidades procesales que dan cuerpo al proceso colectivo en nuestro ordenamiento (arts. 11, $15,221,222.3$ y 519 LEC fundamentalmente).

\footnotetext{
${ }^{1}$ Vid. Gutiérrez de Cabiedes e Hidalgo de Caviedes, P., La tutela jurisdiccional de los intereses supraindividuales: colectivos y difusos, Aranzadi, Navarra, 1999, p. 64.
} 
A la vista de todo ello, la claridad exige que asumamos la delimitación de los conceptos referidos supra.

\section{EL PROBLEMA TERMINOLÓgICO}

Como tuvimos ocasión de avanzar en la introducción, son innumerables las expresiones que han sido empleadas por los autores en el intento de dar nombre a los intereses nacidos de la sociedad de masas. Con este propósito se han empleado sin univocidad alguna las expresiones que a continuación se relacionan: intereses generales ${ }^{2}$, sociales ${ }^{3}$, colectivos $^{4}$, difusos $^{5}$, de categoría ${ }^{6}$, supraindividuales ${ }^{7}$, supraindividuales homogéneos ${ }^{8}$, intereses individuales conexos, superindividuales ${ }^{9}$, pluriindividuales ${ }^{10}$, metaindividuales ${ }^{11}$, transindividuales ${ }^{12}$, plurales ${ }^{13}$ etc., llegando, incluso, a utilizarse como sinónimos ${ }^{14}$.

2 Ésta parece haber sido la expresión escogida por la LEC para hacer referencia a los intereses compartidos por una colectividad de personas. Así se desprende del último inciso del art. 11.1 LEC.

${ }^{3}$ Almagro Nosete, J., Constitucion y proceso, cit., pp. 184 y ss., utiliza esta expresión para referirse a la categoría de intereses que «no se diferencian de lo que son intereses de cada de los miembros del grupo, o categoría, o colectivo de mayor o menor extensión afectado, más que en el sentido comunitario que une a los sujetos afectados y en la posible consideración objetiva de dichos intereses, como causa de tutela diferenciada». Serían subespecies de la categoría de los intereses sociales, los intereses colectivos y difusos.

4 Esta es la expresión utilizada por la Directiva 98/27/CE relativa a las acciones de cesación en materia de protección de los intereses de los consumidores, para referirse a los intereses comunes a la comunidad social de los consumidores.

A su vez, al margen del significado que a esta expresión se anude en el ámbito específico al que ahora nos debemos, este término se encuentra asentado, en nuestro ordenamiento, en el ámbito del derecho del trabajo, donde la tutela de tales intereses se encomienda, no a las empresas y a los trabajadores individualmente considerados, sino a las asociaciones profesionales y sindicatos (art. 17.2 Ley de la Jurisdicción Social).

${ }^{5}$ Así se refiere a los intereses comunes a una comunidad social LozANO-Higuero y PinTo, M., La protección procesal..., cit., pp. 129 y ss.

${ }^{6}$ En la legislación contenciosa administrativa se habla de intereses de categoría o corporativos, en contraposición a las situaciones jurídicas individualizadas aunque sean plurales.

7 Entre otros, GutiéRrez De Cabiedes e Hidalgo De Caviedes, H., La tutela jurisdiccional de los intereses supraindividuales: colectivos y difusos, Aranzadi, Navarra, 1999, utiliza el término intereses supraindividuales como género en el que incluye a los intereses colectivos y difusos, diferenciándoles de los intereses individuales homogéneos.

${ }^{8}$ ARMentA Deu, T., Acciones colectivas: Reconocimiento, cosa juzgada y ejecución, Marcial Pons, Madrid, 2013, p. 69, parece utilizar esta expresión para aludir a la suma de intereses individuales que comparten un mismo origen y tienen un contenido homogéneo. Ello no obstante, no proporciona una definición de los mismos, simplemente los contrapone a los intereses difusos.

9 PROTO PISANI, A., «Appunti preliminari per uno studio sulla tutela giurisdizionale degli interessi collettivi (o piu esattamente: superindividuali) innanzi al giudice civile ordinario», en VV. AA., Le azioni a tutela di interessi colletivi, Cedam, Padova, 1976.

10 GAscón INCHAUSTI, F., Tutela Judicial de los consumidores y Transacciones colectivas, Thomson Civitas, Pamplona, 2010, p.15, se refiere a estos intereses como sinónimos de los intereses individuales homogéneos. 
Ello no obstante, a pesar de que las expresiones incluidas en el totum revolutum referido supra hayan sido utilizadas de modo asistemático por la doctrina, en un afán sistematizador, las mismas podrían ser divididas en dos grandes grupos, que vendrían a corresponderse con las dos modalidades de intereses que podrán ser canalizadas a través de las acciones colectivas. Por un lado, las que serviría al fin de identificar a los intereses pertenecientes a una colectividad de modo indivisible, en el que se incluirían las expresiones: intereses «colectivos $y$ difusos», «transindividuales», «supraindividuales», «superindividuales», «metaindividuales», «sociales» o «generales». Por otro, las que servirían para identificar a la suma de intereses individuales provenientes de un mismo origen y con un contenido homogéneo, al que se adscribirían las siguientes: intereses «pluriindividuales», «plurales», «individuales conexos» o «individuales homogéneos»-.

De entre todas ellas, veamos cuáles son, desde nuestro punto de vista, las expresiones más adecuadas a fin de dar nombre a cada una de las dos situaciones de ventaja a las que acabamos de hacer mención.

En relación a la primera -intereses pertenecientes a una colectividad de modo indivisible-, consideramos que debe ser descartada, en un primer

11 La confusión reinente en la materia es advertida porCAPPELLETTI, M., «Appunti sulla tutela...», cit., p. 199. En igual sentido se pronuncia VILLONE, M., «La collocazione istituzionale dell'interesse diffuso (considerazioni sul sistema statunitense)», en La tutela degli interessi diffusi nel Diritto comparato. Con particolare riguardo alla protezione dell' ambiente e dei consumatori, Giuffrè, Milano, 1976, p. 73.

12 Este es el término empleado por el Código Modelo de procesos Colectivos para Iberoamérica, para referirse a los intereses comunes a una comunidad social, distinguiendo en el género de los intereses transindividuales, como sus dos especies a los intereses colectivos y difusos.

13 La expresión interés plural es utilizada en la Circular del Ministerio Fiscal 2/2010, acerca de la intervención del Ministerio Fiscal en el orden civil para la protección de los consumidores y usuarios, como comprensiva de los intereses colectivos y difusos, al decir expresamente «Ese interés plural al que nos referimos se presenta en la práctica con dos perfiles claramente diferenciados: así, conforme a lo previsto en el artículo 11 de la LEC, cuando los perjudicados por un hecho dañoso son un grupo de consumidores, cuyos componentes están perfectamente determinados o resulta fácilmente determinables, nos hallamos ante intereses colectivos, mientras que en el caso de que los perjudicados por un hecho dañoso sean una pluralidad de consumidores indeterminada o de difícil determinación, los intereses en liza se califican de difusos. En cualquier caso, los intereses supraindividuales, ya sean colectivos o difusos, suponen situaciones jurídicas materiales cuyos titulares no son las personas individuales en cuanto tales, sino en cuanto miembros, determinados o indeterminados, de una colectividad». Para MoNTERo ARocA, J., La legitimación en..., cit., p. 62, el interés plural vendría a identificarse con la suma de intereses individuales.

${ }^{14}$ Gutiérrez de Cabiedes e Hidalgo de Caviedes, P., La tutela jurisdiccional..., cit., p. 64, expresa a estos efectos de manera muy gráfica que «este «baile» de conceptos, en el que se emplea el mismo significante con muy distintos significados y distintos significantes con el mismo significado hace que el terreno por el que se transita se torne enormemente correoso y resbaladizo, constituyendo una célebre rememoración del célebre caos babélico». Por su parte, PARDOLESI, R., «Il problema degliinteressicollettivi e i problema deigiuristi», en Le azioni..., p. 241, habla de un uso desenvuelto -0 si se prefiere incierto- de los términos. 
orden de cosas, la expresión intereses generales. Y es que de ella se hace uso, en ocasiones, en referencia al propio interés público y, como será analizado a continuación, los intereses supraindividuales constituyen un tertium genus en relación al interés público y al interés privado.

Por su parte, tampoco resulta idóneo el empleo de las expresiones «intereses colectivos y difusos», toda vez que éstas han sido utilizadas para designar, como veremos posteriormente, a las dos especies que tienen cabida en el género de los intereses a los que ahora queremos dar nombre, con lo que su uso podría provocar cierta confusión.

Al margen de las expresiones que han sido descartadas, cualquiera de las restantes -intereses «transindividuales», «supraindividuales», «superindividuales», «metaindividuales» o «sociales»-, serviría al fin de calificar esta tipología de intereses, pues a través de todas ellas se pone el acento en la circunstancia de que tales posiciones de ventaja trascienden la esfera individual del sujeto, siendo ésta su característica principal. Ello no obstante, de entre todas las opciones señaladas, nos decantamos por el empleo de la expresión «intereses supraindividuales», por ser ésta la más extendida entre nuestra doctrina.

En otro orden de cosas, en relación a la segunda de las posiciones de ventaja a la que nos hemos referido con anterioridad-la que vendría a identificarse con la suma de intereses individuales provenientes de un mismo origen-, debe descartarse el empleo de las expresiones intereses «pluriindividuales» e «intereses plurales». Y, ello, porque si bien reflejan una afección plurisubjetiva, no aportan ningún indicio en relación al contenido que deben reunir los diferentes intereses involucrados, que como se verá posteriormente, deberán ser homogéneos.

Precisamente porque la premisa anterior sí se observa en las expresiones «intereses individuales conexos» o «intereses individuales homogéneos», ambas servirían para acuñar esta segunda modalidad de intereses. Sin embargo, al igual que en el supuesto anterior, porque su uso se encuentra más extendido entre nuestra doctrina, nos decantamos por el empleo de la segunda de las apuntadas.

Llegados a este punto, una vez que se ha decidido el modo en el que deben ser designadas cada una de las dos tipologías de intereses cuya protección es susceptible de encauzarse a través de la acción colectiva -los intereses supraindividuales y los intereses individuales homogéneos-, corresponde encontrar un término apto en orden a referirnos a ellas de manera conjunta ${ }^{15}$.

A este último respecto, las dos opciones que han sido escogidas por nuestra doctrina han sido, por un lado, la expresión «intereses

15 Esta necesidad fue apuntada ya por BujOSA VADELL, en BUJOSA VADELL, L. M. , La protección jurisdiccional de los intereses de grupo, J. M., Bosch, Barcelona, 1995, p.p. 81,174 y 260 a 261 , el cual optó por la expresión «intereses de grupo» para identificar al conjunto de situaciones de ventaja, de naturaleza jurídica diversa, nacidas de las sociedad de masas. Reacio a la búsqueda de un denominador común al estilo del mencionado, se ha mostrado GutiérRez de Cabiedes e Hidalgo De CAVIEDes, P., La tutela jurisdiccional..., cit., p. 112, pie 152, al considerar que de este modo se dificulta la delimitación de la tipología de intereses a que viene referido. 
colectivos» ${ }^{16} \mathrm{y}$, por otro, la de $\left\langle\right.$ intereses de grupo» ${ }^{17}$. El uso de la primera resulta desaconsejable, en esencia, porque a esta expresión se han anudado significados muy diversos ${ }^{18}$ y la segunda, por cuanto la

16 Opción por la que se han decantado, entre otros, GASCON INCHAUSTI, F., Tutela Judicial de los consumidores y Transacciones colectivas, Thomson Civitas, Cizur Menor (Navarra), 2010, p. 15; ARMENTA DeU, T., Acciones colectivas: Reconocimiento..., cit., p. 32; BACHMAIER WINTER, L., «Informe de España sobre «Acciones populares y acciones para la tutela de los intereses colectivos», 2001, p. 5, citada en OVALLE FAVELA, J., «Acciones populares y acciones para la tutela de los intereses colectivos», Ponencia general presentada en el XIII «Seminario Internazionale su formazione e caratteri del Sistema giuridico lateniomericano e problema del proceso civile», organizado por el Centro di Studi Giuridici latinoamericani del Consiglio Nazionale delle ricerche, la Università «TorVergata» de Roma, el Instituto italo-latinoamericano y el Instituto iberoamericano de Derecho Procesal, en Roma, del 16 al 18 de mayo de 2001. Disponible en: http//: www.ejournal.unam.mx/boletín_mderecho/bolmex107/BDM10706pdf. Consultado el 31 de agosto de 2016; en la definición que proporciona de «intereses colectivos», incluye tanto los intereses supraindividuales como los intereses individuales homogéneos. Enfrenta los intereses difusos que define como «aquellos intereses que afectan a una comunidad de sujetos amplia e indeterminada, no existiendo vínculo o nexo entre ellos», a los intereses colectivos, que se persiguen «cuando un grupo se encuentra en una misma situación jurídica o cuando una pluralidad de sujetos se ven afectados por un mismo hecho y los integrantes del grupo o los afectados están determinados o pueden ser determinados sin dificultad».

Ésta ha sido también la expresión utilizada en la Exposición de Motivos de la LEC, por cuanto dispone que «A propósito de las partes, aunque en verdad desborde ampliamente lo que es su reconocimiento y tratamiento procesal, parece oportuno dar razón del modo en que la presente Ley aborda la realidad de la tutela de intereses jurídicos colectivos, llevados al proceso, no ya por quien se haya visto lesionado directamente y para su individual protección, o por grupos de afectados, sino por personas jurídicas constituidas y legalmente habilitadas para la defensa de aquellos intereses» (apdo. VII).

${ }^{17}$ Entre nuestra doctrina, ésta es la opción por la que se ha decantado BUJOSA VADELL, L. M., La protección jurisdiccional..., cit., passim., que utiliza el concepto (siguiendo a THIERE, K.) para englobar a los intereses supraindividuales y a los intereses individuales homogéneos. También se decantan por esta terminología DE LUCCHI LÓPEZ-TAPIA, Y., La tutela jurisdiccional civil de consumidores y usuarios, Edisofer, Madrid, 2005., pp. 31 y ss.; Álvarez AlARCón, A., «La protección de los consumidores y usuarios: intereses individuales e intereses de grupo», en Alonso-Cuevillas SAYROL, J., Instituciones del nuevo proceso civil. Comentarios sistemáticos a la Ley 1/2000, vol. 1, Barcelona, 2000, pp. 229 y ss. Por el mismo denominador común se ha decantado DeLGADo RodRíGUEZ, A. F., «Intereses plurales: Análisis de su protección procesal en Estados Unidos como opción de desarrollo del 9.20 C.E. y del art. 7.30 L.O.P. J.», en Anales de la Facultad de Derecho, Universidad de la Laguna, núm. 16, 1999, p. 63, En la doctrina brasileña GIDI, A., «Las acciones colectivas y la tutela de los derechos difusos, colectivos e individuales en Brasil. Un modelo para países de Derecho Civil», Doctrina Jurídica, núm. 151, UNAM, México, 2004, utiliza la expresión «intereses de grupo» como comprensivo de los intereses transindividuales (colectivos y difusos) y los intereses individuales homogéneos.

18 Según el parecer de AcostA EstéVEZ, J. B., Tutela procesal de.., cit., p. 41, el interés colectivo es una expresión altamente equívoca, precisamente, porque es susceptible de adoptar sentidos diferentes y absolutamente contradictorios, según sea utilizado por los distintos estudiosos de la materia en el área de las diferentes disciplinas jurídicas. En igual sentido, indica PROTO PISANI, A., «Appunti preliminari per uno studio sulla tutela giurisdizionale degli interessi collettivi (o piu esattamente: superindividuali) innanzi al giudice civile ordinario», en VV. AA., Le azioni a tutela di interessi colletivi, Cedam, Padova, 1976, p. 263, (aunque emplea el término colectivos para referirse a los intereses 
referencia al grupo evoca una realidad acotada, que a nuestro juicio sería más próxima a los conflictos con afectados determinados y más lejana, sin embargo, a los supuestos de indeterminación de afectados.

Tras valorar las distintas posibilidades, se ha optado por una expresión distinta, cual es la de «intereses de incidencia social de los consumidores», porque, por un lado, los intereses supraindividuales -como será posteriormente examinado- son intereses sociales en sentido estricto; y, por otro, los intereses individuales homogéneos, si bien en su génesis son intereses privativos, su lesión presenta cierta relevancia social - no sólo por la magnitud de afectados sino también por el carácter de la infracción-, que es la que a la postre permite que los intereses concurrentes sean tutelados por medio de un cauce procesal conjunto ${ }^{19}$.

Así, podrían ser definidos los «intereses de incidencia social de los consumidores» como aquellos que pertenecen divisible o indivisiblemente a una pluralidad relevante de consumidores o a una comunidad social, desbordando, por las características que les son propias, los mecanismos tradicionales de acceso al proceso ${ }^{20}$.

Llegados a este punto corresponde arrojar luz, de modo ya más pausado, sobre el contenido con el que deba llenarse esta genérica expresión que, como ya ha sido adelantado supra, se encierran dos situaciones jurídicas de distinta naturaleza, por un lado, las que vendrían a corresponderse con los intereses «supraindividuales» $y$, por otro, las configuradoras de los «intereses individuales homogéneos».

superindividuales), que «l'espressione "interessi collettivi" è- almeno cosí come è adoperata negli scritti recenti- una espressione altamente equivoca. Partecipando ai congressi dedicati all'argomento si ha l'impressione (ma è piú una impressione) che l'espressione sia adoperata in significati spesso radicalmente diversi dagli amministrativisti, dai civilisti, dai constituzionalisti, dai giuslaboralisti: ciascuno ha presente dei fenomeni eproblemi particolari- nonsempre esplicati- e con referimento ad essi ed a essi soli tischia spesso di svolgere un discorso che almeno aparentemente, ha la pretesa della generalità».

${ }^{19}$ Como indica Montero Aroca, J., De la legitimación en el proceso civil, Bosch, Barcelona, 2007, p. 409, el paso de los intereses acumulables a los intereses individuales homogéneos, o lo que es lo mismo, lo que lleva a la tutela colectiva de los derechos subjetivos concurrentes no lo es sólo la existencia de un hecho común que afecta a los derechos o intereses de un conjunto mayor o menor de personas, sino la relevancia social del daño causado.

De ahí que el Ministerio Fiscal, con fundamento en el art. 124 CE que le confiere la misión de «procurar ante los tribunales la satisfacción del interés social» se encuentre legitimado en orden a la interposición de acciones colectivas en defensa de los unos y de los otros. Y es que tal y como será examinado en sede de legitimación, el Ministerio Fiscal, de conformidad con art. 11.5 LEC, podrá interponer cualesquiera acciones en defensa de los intereses «colectivos y difusos» de los consumidores.

${ }^{20}$ Esta definición se inspira en la proporcionada por GIANNINI en torno a los que, en el panorama argentino se han dado en llamar «intereses de trascendencia colectiva», comprensivos, igualmente, de los intereses supraindividuales e individuales homogéneos. GiANNINI, L. J., «La tutela colectiva de derechos individuales homogéneos en la Argentina (Marchas y contramarchas del Proyecto de Código Civil y Comercial)», en Revista de Derecho Procesal, Rubinzal Culzoni, núm. 2013-1, «Proyecto de Código Civil y Comercial. Aspectos procesales», p. 256. 


\section{LOS INTERESES SUPRAINDIVIDUALES}

Los intereses supraindividuales pueden ser definidos con carácter general como una categoría de intereses comunes o de pertenencia indivisible a una comunidad social, siendo esta última la que ostenta su titularidad ${ }^{21}$.

En el ámbito de los sistemas de civil law, la doctrina italiana ha sido, sin lugar a dudas, la que mayores esfuerzos ha dedicado a su estudio ${ }^{22}$, con especial incidencia a partir de los años setenta ${ }^{23}$. Pese a ello, los estudios emprendidos en Italia vieron recompensados sus esfuerzos, principal y paradójicamente, en Brasil ${ }^{24}$, que se convirtió en el primero de entre los sistemas de civil law que introdujo en su ordenamiento jurídico la tutela de los intereses supraindividuales, denominados en el sistema brasileño como derechos transindividuales - colectivos y difusos ${ }^{25}$.

21 Como explica Montero ArocA, J., De la legitimación..., cit., p. 410, la titularidad de estos intereses no puede referirse ni a una persona ni a varias personas consideradas en su individualidad, ya que el interés mismo únicamente se explica en referencia al propio grupo.

22 El primer estudio monográfico sobre los intereses supraindividuales (en concreto, en relación al interés colectivo) es el elaborado por BonAUDI, E., La tutela degli interesi diffussi, Bocca, Torino, 1911.

23 En el período que se extiende desde mediados de los años setenta a principios de los ochenta, puede constatarse un especial despliegue doctrinal en la materia. Los que a continuación se enumeran son tan sólo algunos de los trabajos que veían la luz por aquel entonces: TARUFFO, M., «I limiti soggettivi del giudicato e le «class actions»», en Rivista di Diritto Processuale, 1969; CARPI, F., L'efficacia ultra partes della sentenza civile, Milano, 1974; CAPPELLETTI, M., «Formazioni social e interessi di grupo davanti alla giustizia civile», en Rivista di Diritto Processuale, 1975; ALPA, G., Responsabilità dell'impresa e tutela del consumatore, Milano, 1975; GAMBARO, A., La tutela degli interessi diffusi nel diritto comparato, Milano, 1976; VIGoRITI, V., Interessi collettivi e..., cit. A su vez, parte de este impulso se refleja en la organización de numerosos congresos dedicados a la profundización en el estudio de los nuevos intereses objeto de tutela, entre ellos, podemos citar a título de ejemplo, el celebrado en Pavia los días 11 y 12 de junio de 1974, el celebrado en Salerno, del día 22 a 25 de mayo de 1975, el de Varenna del 22 a 24 de septiembre de 1977, o el celebrado en Bolonia el 5 de diciembre de 1982.

${ }^{24}$ Cfr. TARUfFO, M., «La tutela collettiva: interessi in gioco ed esperienze a confronto», en BelLI, C., Le azioni collettive in Italia. Profili teorici ed aspetti applicativi, Giuffrè, Atti al convegno-Roma, 16 de febrero 2007, p. 13; y PELLEGRINI GRINOVER, A., «La difessa degli interessi transindividuali: Brasile e Iberoamerica», en LANFRANCHI, L. (Dir.), La tutela giurisdizionale degli interessi collettivi e diffusi, Giappichelli, Torino, 2003, p. 157.

25 En Brasil, la tutela de los intereses transindividuales se introdujo por medio de la reforma de la Ley de la Acción Popular en el año 1977 y, posteriormente, a través de la Ley de acción civil pública de 1985. Sin embargo, la regulación más amplia y sistemática de las acciones colectivas se introdujo en el Código de Defensa del Consumidor del 11 de septiembre de 1990, cuyo art. 81 distingue tres tipos de intereses o derechos colectivos: los difusos, los colectivos y los individuales homogéneos. De acuerdo con el párrafo único de ese artículo, son difusos los intereses o derechos «transindividuales, de naturaleza indivisible, de que sean titulares personas indeterminadas y ligadas por circunstancias de hecho»; en cambio, son colectivos (en sentido estricto) los intereses «transindividuales, de naturaleza indivisible, de que sea titular un grupo, una categoría o una clase de personas ligadas entre sí o con la parte contraria por una relación jurídica base».

Por su parte, en el contexto italiano actual, el código de consumo distingue, por un lado, los intereses colectivos en sentido estricto, que vendrían a corresponderse con los intereses supraindividuales, (art. 139) y, por otro, los intereses individuales homogéneos (art. 140 bis). A su vez, pueden diferenciarse en Italia, en función del interés cuya tutela 
En España, la doctrina especializada no comenzó a fijar en ellos su atención hasta el inicio de la década de los ochenta, elaborándose la mayor parte de los estudios a su respecto a partir de los noventa ${ }^{26}$. El término elegido en un primer momento para aludir a los intereses supraindividuales fue en nuestro país el de «intereses difusos», posteriormente se empezó a hablar también de «intereses colectivos o de grupo» y, en la actualidad, son mayoritariamente acuñados por la doctrina como intereses supraindividuales. Sin embargo, la terminología empleada por los autores no encuentra su reflejo en la LEC del 2000, que se refiere a ellos, por una lado, como intereses generales (art. 11.1 LEC) y, por otro, como «intereses colectivos y difusos» (arts. 11.4 y 15.4 LEC, entre otros).

\subsection{NATURALEZA JURÍDICA}

En torno a la naturaleza jurídica de los intereses supraindividuales ha existido gran confusión, hasta el punto de que han sido considerados como «una nebulosa de contornos vagos y oscilantes» ${ }^{27}$. En concreto, son tres los ejes de la discordia que han avivado el debate doctrinal en esta sede: por un lado, el referente a su consideración como una suma de intereses individuales o como una situación de ventaja única; en segundo término, el relativo a su posible encuadre en las clásicas figuras de los

se pretenda, dos tipos de procesos, por un lado, los juicios colectivos propios o inhibitorios, en los que se ventilan los intereses colectivos y, en segundo lugar, los juicios colectivos impropios o reparadores, que serían los reservados a la tutela de los intereses individuales homogéneos.

${ }^{26}$ Entre las primeras obras dedicadas a la materia, deben ser citadas: LOZANO-HIGUERO Y PINTO, M., La protección procesal..., cit.; AcOSTA ESTÉVEZ, J. B., Tutela procesal de..., cit.; BUJOSA VADELL, L. M., La protección jurisdiccional..., cit.; GUTIÉRREZ DE CABIEDES E HIDALGO DE CAVIEDES, P., La tutela jurisdiccional..., cit. Tras la promulgación de la LEC $1 / 2000$, por su parte, destacan, entre otras: GonzÁLEZ CANO, M. I., La tutela colectiva de consumidores y usuarios en el proceso civil, Tirant lo Blanch, Valencia, 2002;BARONA ViLAR, S. (Coord.), Tutela de los Consumidores y usuarios en La Ley de Enjuiciamiento Civil, Tirant lo Blanch, Valencia, 2003; SiLgUero ESTAGNAN, J., La tutela jurisdiccional de los intereses colectivos a través de la legitimación de los grupos, Dykinson, Madrid, 2005; CABAÑAS GARCía, J. C., Los procesos civiles sobre consumidores y usuarios y de control de las cláusulas generales de los contratos (con jurisprudencia asociada), Tecnos, Madrid, 2005; DE LUCCHI LÓPEZ-TAPIA, Y., La tutela jurisdiccional..., cit. Por último, entre las monografías más recientes, se encuentran las siguientes: GASCÓN INCHAUSTI, F.,Tutela Judicial de los Consumidores y Transacciones Colectivas, Thomson Reuters, Pamplona, 2010; ARIZA ColmenAREjo, M. J., La acción de cesación como medio para la protección de consumidores y usuarios, Aranzadi, Navara, 2012; ARMENTA DEU, T., Acciones colectivas: Reconocimiento..., cit.; y PLANCHADell GARgallo, A.,Las "acciones colectivas" en el ordenamiento jurídico español. Un estudio comparado, Tirant lo Blanch, Valencia, 2014.

${ }^{27}$ PARDOLESI, «Il problema degli interessi collettivi e i problema dei giuristi», in Le azioni a tutela degli interessi collettivi, cit., p. 241. Por su parte, VILLONE, «La collocazione istituzionle dell'interesse diffuso (Considerazione al sistema statounitense)», in La tutela degli interessi diffusi nel diritto comparato: con particolare riguardo alla protezione dell'ambiemte e dei consumatori, Giuffrè, Milano, 1979, p. 71 y ss., spec. p. 73, se refiere a los mismos como «personajes absolutamente misteriosos». En la misma línea, FAIRÉn se refería a ellos como «difusos, profusos o confusos», en FAIRÉN GUILLÉN, V., Doctrina general del Derecho Procesal. Hacia una teoría y ley procesal generales, Bosch, Barcelona, 1990, p. 93. 
derechos subjetivos e intereses legítimos; y, por último, su acomodo en la tradicional dicotomía intereses públicos-intereses privados 0 su consideración como un tertium genus.

3.1.1. Suma de intereses individuales vs. categoría autónoma En las primeras reflexiones formuladas por la doctrina italiana en relación a la naturaleza de los intereses supraindividuales, éstos, lejos de ser considerados como una categoría jurídica autónoma, eran reconducidos a la mera «suma» de intereses individuales. Esta concepción era el resultado de la visión liberalista del individuo a la sazón vigente, merced a la cuál éste se hallaba completamente aislado de cualquier relación social $^{28}$.

A día de hoy, si bien los intereses supraindividuales son concebidos por la práctica unanimidad de los autores como una categoría autónoma respecto a los intereses individuales o de su mera adición, lo cierto es que persiste cierta confusión a la hora de identificar su presencia en la práctica, entremezclándose, en ocasiones, con los propios intereses individuales homogéneos que, como veremos infra, sí se corresponden con la suma de derechos subjetivos individuales. Con base en la potencial confusión entre los unos y los otros, la Directiva 98/27/CE, del Parlamento Europeo y del Consejo, relativa a las acciones de cesación en materia de protección de los intereses de los consumidores (en adelante, Directiva $98 / 27 / \mathrm{CE})^{29}$, al definir los intereses supraindividuales ${ }^{30}$, incide en que éstos no deben identificarse con una acumulación de intereses de particulares que se hayan visto perjudicados por una infracción.

Con todo, una vez superada la visión atomizada o «molecular» de los intereses supraindividuales, se ha advertido la presencia de múltiples teorías que, admitiendo su sustantividad propia, han intentado conceptualizarlos. Sin perjuicio de las numerosas aportaciones doctrinales a este respecto, se traerán aquí tan sólo aquellas tesis que, por su especial trascendencia, pueden ser consideradas representativas del sentir doctrinal mayoritario. Éstas son, de un lado, la tesis objetiva, centrada en la especial naturaleza del bien o derecho al que vienen referidos estos intereses $\mathrm{y}$, de otro, la tesis subjetiva, asentada sobre el elemento personal del interés ${ }^{31}$.

\footnotetext{
${ }^{28}$ Cfr. SolARI, G., Individualismo e diritto privato, Torino, 1911, reimpresión 1959, pp. 341 y ss.

29 La Directiva 98/27/CE fue derogada por la Directiva 2009/22/CE, del Parlamento Europeo y del Consejo, de 23 de abril de 2009, relativa a las acciones de cesación en materia de protección de los intereses de los consumidores.

30 Es necesario aclarar que este instrumento utiliza la expresión «intereses colectivos» en relación a lo que en estas líneas han sido acuñados como intereses supraindividuales.

${ }^{31}$ BUJOSA VADELL, L. M., La protección jurisdiccional..., cit., pp. 69 y ss., señala además de los ya citados, el criterio normativo, según el cual la consideración de un interés como supraindividual o de grupo, estaría supeditado a su previo reconocimiento como tal en el ordenamiento jurídico. Ello no obstante, puntualiza el autor que dicho criterio carece de relevancia práctica, centrando el estudio en los dos restantes. En la misma línea GonzÁlez CANo, M. I., La tutela colectiva..., cit., pp. 20 a 22, descarta la operatividad del
} 
Entre los propulsores de la primera destaca SANTORO PASARELLI, quien siguiendo la corriente iniciada por CARNELLUTTI en los años treinta ${ }^{32}$, propone una noción de interés supraindividual que incide sobre su carácter indivisible ${ }^{33}$, carácter éste del que vendría a derivarse la necesidad de su tutela conjunta. Así, el interés supraindividual, que se configuraría, no ya como la suma de intereses individuales, sino como su «síntesis» o «combinación», sería definido como el interés de una

criterio normativo aduciendo, de un lado, que ello obligaría al legislador a desarrollar una ingente y casuística labor normativa $y$, de otro, por la imposibilidad de acotar materialmente el conjunto de fenómenos que a los mismos dan lugar.

32 Recordemos que de conformidad con la tesis de CARNELLUTTI existen intereses supraindividuales -a los que califica, sin embargo, como colectivos- cuando la situación favorable a la satisfacción de una necesidad no puede determinarse sino respecto a varios individuos a la vez, o en otros términos, cuando la situación favorable a cada individuo, para la satisfacción de una necesidad suya, no puede determinarse sino junto a otras idénticas situaciones favorables de los demás miembros de un determinado grupo. A los efectos de ilustrar su posicionamiento señala dos ejemplos de bienes, una casa (divisible) y una gran vía de comunicación (indivisible). El disfrute de la casa podría constituir un interés individual, pues una sola persona puede tener una casa para sí, por la contra, el disfrute de una gran vía de comunicación constituiría un interés colectivo, por cuanto esta no puede abrirse para satisfacer las necesidades de un solo hombre, sino para satisfacer las necesidades simultáneas de muchos hombres. Como puede apreciarse, esta concepción pone el acento sobre la especial actitud del bien en orden a ser disfrutado contemporáneamente por varios sujetos, de modo que intereses colectivos serían tan solo los referidos a bienes indivisibles. Cfr. CARnELUTTI, F., Sistema de Derecho..., cit., pp. 11 y ss.; también han seguido esta teoría objetiva del interés, РROTO PISANI, A., «Appunti preliminari per...», cit, p. 264; CosTANTINO, G., «Brevi note sulla tutela giurisdizionale degli interessi collettivi davanti al giudice civile», en Le azioni a tutela di interessi colletivi, Cedam, Padova, 1976, p. 231; D'ONOFRIO, F., «Prime reflessioni sul Diritto di acceso alla radiotelevisione» en La tutela degli interessi difussi nel diritto comparato, Giuffrè, Milano, 1976, p. 16; JAEGER, P. G, L'interesse sociale, Milano, 1964 , p. 3; JAEGER, N.,Corso di diritto processuale civile, Milano, 1956, p. 8 y ss.

33 En el Derecho brasileño, la indivisivililad de los derechos metaindividduales (colectivos y difusos) fue apuntada por BARBOSA MOREIRA, «A ação popular do direito brasileiro como instrumento de tutela jurisdiccional dos chamados "intereses difusos"», en Temas de Direito Processual, S.P., Saraiva, 1977, p. 111 a 112; En palabras de GIDI, A., «Class action and "amparo colectivo" in Brazil. The protection of diffuse, collective and homogeneous individual rights» (trad. de LuCIO CABRERA ACEVEDO y EdUARDO FERRER MACGregor), en Derecho Procesal Constitucional, vol. 3, EduARdo Ferrer MAC-Gregor, Porrúa, México, Suprema Corte de Justicia, Colegio de Secretarios, 2003, p. 352, la indivisibilidad «significa que resulta imposible dividir el derecho en cuotas atribuibles a cada uno de los miembros del grupo; los intereses de los miembros se encuentran tan cercanamente relacionados que, cuando la reparación es conferida a un miembro, ello implica satisfacción de los reclamos de cada miembro del grupo, y cuando los derechos de uno de los miembros son violados, ello implica violación de los derechos de todo el grupo»; VIGORITI, V., Interessi collettivi e..., cit., p. 20, critica esta teoría al decir que «una cosa è il fatto che le aspirazioni siano tutte dirette verso il conseguimento del medesimo bene, altra cosa è affermare che l'obbiettiva indivisibilità debba essere una caratteristica constante del bene a cui aspirano gli interesse correlati. Il collettivo può benissimo formarsi per soddisfare aspirazioni verso beni obbietivamente divisibbili, e in astratto magari anche individualmente perseguibili, ma a guidizio dei cointeressati meglio coordinando le iniziative», si bien semeja que el autor se está refiriendo a una realidad diversa, esto es, aquella que vendría a corresponderse con los intereses individuales homogéneos. 
pluralidad de personas en relación a un único bien idóneo en orden a la satisfacción de una común necesidad ${ }^{34}$.

Por su parte, desde la perspectiva de la doctrina subjetiva, sobresale la tesis de VigoritTI, quien siguiendo la línea iniciada también en los años treinta, en este caso por CESARINI SFORZA ${ }^{35}$, considera que el núcleo central del fenómeno que designa como «colectivo» radica «no en una anónima, y quizás involuntaria, conjunción objetiva de intereses, sino en una elección dictada por la conciencia de la dimensión no exclusivamente individual de ciertas aspiraciones, y por consiguiente por la voluntad de llegar a una coordinación de las manifestaciones dirigidas a alcanzar una finalidad común» 36 .

A la vista de las dos teorías enunciadas, trataremos de demostrar la idoneidad de la primera en detrimento de la segunda, en orden a caracterizar lo que por interés supraindividual deba entenderse. Se hará por medio de un ejemplo:

Si se anuncia televisivamente un producto falseando sus propiedades, los destinatarios de la publicidad emitida, con independencia de cuál sea su valoración respecto al carácter del interés en juego, resultarán de facto afectados de modo concurrente y no exclusivo por la misma antijuricidad $^{37}$. Ello es consecuencia, únicamente, del tipo de bien jurídico

34 SANTORo Passarelli, F., Nozioni di diritto del lavoro, Napoli, 1995, p. 29, de manera más concreta, el autor dice expresamente que se trata de un interés que «non può essere conseguito dai singoli separatamente, ma solo congiuntamente da tutti».

35 Para Cesarini Sforza, W.,Lezioni di teoria generale del diritto I, Padova, 1931, p. 130, al lado de la figura del interes individual «si presenta anche l'interesse generale, formato dalla somma delle valutazione di coloro che compongono una collettività atraverso lo spazio e nella sucessione del tempo». De conformidad con su tesis, la consideración de un interés como supraindividual -aunque el autor habla de interés general- no resultaría del carácter del bien al que venga referido, sino de la intención de los individuos afectados de referir el interés, no a sí mismos, sino a la colectividad de la que forman parte Este interés general, sin embargo, no vendría a identificarse con el interés de cada uno de los miembros de la colectividad individualmente considerados, uti singulis, sino con el interés de cada uno de ellos en cuantos miembros de la colectividad, uti socius $o$ uti civis. A su vez, para que se pueda hablar de voluntad general o colectiva es necesario que la suma de las aspiraciones de los miembros del grupo se convierta -a través de un juicio interpretativo confiado a un ente exponencial-, en una aspiración común imputable a la categoría como un todo. De ahí que la organización del grupo sea su nota característica.

36 En tal sentido, Vigoriti, V., Interessi collettivi e..., cit., pp. 22 a 23, considera que la ausencia de organización implicaría la inexistencia del interés colectivo, dando lugar a una sencilla comunidad de intereses. La ventaja o desventaja que de las actuaciones aisladas de uno de los miembros del grupo produjese en los demás, no sería más que una circunstancia meramente accidental: una consecuencia refleja y no voluntaria.

De acuerdo con esta corriente GiAnNini,M., «La tutela degli interessi collettivi nei procedimenti», en VV. AA., Le azioni a tutela di interessi colletivi, Cedam, Padova, 1976, p. 23, caracteriza los intereses colectivos como aquéllos que tienen como portador un ente exponencial de un grupo no ocasional. A la teoría de este autor haremos referencia posteriormente con ocasión de la distinción entre intereses colectivos y difusos.

37 Ello no implica, sin embargo, que el criterio subjetivo no sea válido en orden a definir otro tipo de intereses nacidos de ilícitos pluriofensivos, muy al contrario, a su través podrán caracterizarse los intereses individuales homogéneos. La intención de los 
que disfrutan, en el caso expuesto, la obtención de información veraz relativa a los bienes y servicios que puedan adquirir o contratar. Como consecuencia del carácter indivisible del bien jurídico protegido, si un ente legitimado al efecto, póngase por caso el Ministerio Fiscal, ejercita la pretensión de cese y la publicidad declarada engañosa deja de emitirse, no cabrá el ejercicio de pretensiones ulteriores en relación al mismo objeto, pues su ejercicio por uno de los legitimados agota el ejercicio de la acción $^{38}$. Esta última característica es la consecuencia del carácter indivisible que del interés supraindividual se predica y que a la postre impide que respecto de dicho interés puedan concebirse juicios individuales ${ }^{39}$.

perjudicados es determinante en el supuesto de que un mismo ilícito afecte individualmente a un conjunto más o menos definido de sujetos, pues tan sólo la voluntad de los afectados podrá producir que los intereses concurrentes, manteniendo su carácter privativo, adquieran una dimensión plural que permita su contemplación conjunta.

A su vez, la consideración grupal del conjunto de afectados por el mismo acto reprochable permitirá que el interés del que son individualmente titulares pueda ser defendido en juicio a través de una «acción colectiva» entablada por alguno de los legitimados (arts. 11.2 y 3 LEC). En caso contrario, cada uno de los intereses individuales concurrentes tendrá tan sólo la dimensión privada que su titular ha decidido otorgarle.

Así las cosas, de lo dicho se colige que la teoría subjetiva del interés colectivo, en todo caso $y$, con cierto matices, vendría referida a los intereses individuales homogéneos $y$ no, como pretendía, al interés supraindividual o colectivo.

${ }^{38}$ Los intereses concurrentes, tal y como explica DONZELLI, R., La tutela giurisdizionale..., cit., p. 272, son aquellos intereses compatibles, por cuanto «non solo il realizzarsi dell'uno non esclude il realizzarsi dell'altro [...], ma al realizarsidell'unoconseguenecessariamenteilrealizzarsedell'altro».

39 Sobre el concepto de indivisibilidad vid. GIDI, A., «Class action and...», cit., p. 908.

Al respecto de la imposibilidad de sustanciarse procesos individuales como consecuencia del carácter indivisible del bien jurídico protegido, cabe señalar que no obstante la conclusión plasmada en el texto, no ha sido cuestión pacífica entre la doctrina. En sentido favorable al aquí sostenido se han mostrado, entre otros, GAScón INCHAUSTI, F., Tutela judicial de..., cit., p. 143, quien defiende que no es concebible la existencia de procesos individuales respecto de los derechos supraindividuales; también MARÍn LóPEZ, J. J., en Bercovitz, R.; SALAS, J. (CoORd.), Comentarios a La Ley General para la defensa de los Consumidores y Usuarios, Madrid, 1992, p. 555; y GIDI, A., «Class action and...», cit., p. 908.

En el extremo opuesto se ha pronunciado MonTERo ARocA, J., De la legitimación..., cit., p. 411, al afirmar que «estos intereses si bien son comunes a varios o muchos individuos, en ellos no se llega a perder la individualidad, por lo que pueden concebirse respecto de ellos procesos individuales».

A medio camino entre la concepción del interés supraindividual como suma de intereses individuales y la posición que acaba de ser explicada, nos encontramos con la tesis promovida, en el seno de nuestro ordenamiento jurídico, por GUTIÉRREZ DE CABIEDES E HidALGo DE CAVIEDES, P., La tutela jurisdiccional..., cit. pp. 77 a 78, para quien el interés supraindividual estaría integrado por una pluralidad de situaciones subjetivas referidas a sujetos particulares, de manera tal que cualquiera de ellos podría, de modo autónomo, perseguir la satisfacción de su interés privativo. Ello no obstante, aclara este autor que las posiciones subjetivas individualizadas no vendrían a identificarse con los intereses individuales en el sentido en que estos últimos han sido tradicionalmente concebidos, por cuanto no constituyen posiciones subjetivas exclusivas, sino que dan lugar a situaciones jurídicas análogas, compartidas, cuyos titulares se hallan unidos por un mismo fin. 
En el camino hacia la delimitación de lo que por intereses supraindividuales deba entenderse, resultan interesantes las dos notas que Proto PisAni les atribuye: no dan lugar al fenómeno del litisconsorcio necesario, en cuanto se apartan del sector de la cotitularidad; y el comportamiento de un solo sujeto (el obligado) debe satisfacer contemporáneamente los intereses de la totalidad de las situaciones de ventaja correlativas ${ }^{40}$.

\subsubsection{Derechos subjetivos e intereses legítimos}

La doctrina se divide a este respecto entre quienes consideran que los intereses supraindividuales tienen cabida en las categorías tradicionales de los derechos subjetivos y los intereses legítimos -ambos colectivos- y quienes defienden que éstos configuran un tertium genus ${ }^{41}$.

Para los últimos, las situaciones de ventaja supraindividuales vendrían a erigirse en elementos jurídicos autónomos respecto de las figuras tradicionales del derecho subjetivo y del interés legítimo, pues no hallan elementos comunes entre éstas y las situaciones de ventaja tradicionalmente reconocidas por el ordenamiento jurídico ${ }^{42}$.

En relación a los primeros pueden distinguirse dos posicionamientos: por un lado, el de los autores que optan por la reconducción de los intereses supraindividuales tanto a los derechos subjetivos como a los intereses legítimos ${ }^{43}$; y la de los autores que, con base en la rigidez que caracteriza

\footnotetext{
40 Proto PisAni, A., «Appunti preliminari per...», cit., p. 263.

41 Tal y como explica GutiérRez de CABiedes E Hidalgo de Caviedes, P., La tutela jurisdiccional..., cit., pp. 92 a 93, la expresión tertium genus se utiliza -en el marco del estudio de la naturaleza de los intereses supraindividuales- con varias acepciones. Por un lado, se emplea por quienes defienden que estos intereses se configuran como elementos alternativos al derecho subjetivo y al interés legítimo y, por otro, es utilizado por aquel sector doctrinal que defiende que estas posiciones de ventaja vendrían a ocupar una posición intermedia entre el interés privado y el interés público.

${ }^{42}$ En este sentido, sostiene ZANUTtigh, L., «Interventi», en STANZANI, D.; FIORE, A. (Eds.), Strumenti per la tutela degli interessi della collettività, Maggioli Editore, Rimini, 1981, p. 175, que «il solo fatto che alla titolarità di un diritto-interesse ambientale non corrisponda un potere o una forma di privilegio esclusivo e differenziato e che la tutela in sede giudiziale coinvolga inevitabilmente un'area estremamente estesa di aspettative giuridiche di identico contenuto, palesa la non riconducibilità degli interessi-diritti medesimi agli schemi ricostruttivi propri delle posizioni private di tipo esclusivo». En igual sentido, DENTI, V., «Profili civilistici della tutela degli interessi diffusi», en AA.VV., Strumenti per la tutela degli interessi della collettività, Maggioli Editore, Rimini, 1981, p. 43.

En este sentido se pronuncia LOZANO-HIgUeRo Y PiNTO, M., «De nuevo sobre la tutela de los intereses difusos (en especial el patrimonio histórico artístico)», en Justicia, 1996, p. 309 , al sostener que el interés sustentador o legitimante de la pretensión, no es un interés legítimo, por supuesto nunca el derecho subjetivo y tampoco cualquier interés directo, sino un interés reflejo

${ }^{43}$ Ésta es la posición sostenida, entre otros, por VIGORITI, V., Interessi collettivi e..., cit., pp. 24 a 32, que considera que siempre que nos encontremos con un interés difuso o colectivo estaremos ante un derecho subjetivo «colectivo»o ante un interés legítimo «colectivo».
} 
al derecho subjetivo, los consideran reconducibles tan sólo a los intereses legítimos.

Esta última sería la posición seguida, con carácter general, por nuestra doctrina $^{44}$. La razón de ello estriba, como advierte BuJOSA VADELL, en que el «derecho» sigue conectándose en el ámbito de nuestro ordenamiento con las situaciones subjetivas de ventaja de corte clásico, individualistas y patrimonialistas, mientras que el de «interés» se ha beneficiado de mayor flexibilidad que ha permitido una evolución más acorde con los tiempos ${ }^{45}$, de ahí que se haya admitido la existencia de intereses legítimos colectivos y no de derechos subjetivos colectivos.

La concepción puramente individualista del derecho subjetivo es una característica propia de los sistemas de civil law, fuertemente influenciados por la dogmática jurídica tradicional. Una excepción la encontramos, sin embargo, en Latinoamérica, pues a pesar de que el Código Modelo de Procesos Colectivos para Iberoamérica se refiera a los «derechos e intereses»-probablemente por la fuerte influencia de los estudios de la doctrina italiana-, la doctrina se ha decantado, de modo generalizado, por el uso del término «derechos». En igual sentido, entre otros, el propio Código del consumidor brasileño, opta directamente por el uso de las expresiones «derechos transindividuales colectivos y difusos» y «derechos individuales homogéneos» ${ }^{46}$.

Los derechos de trascendencia colectiva han sido reconducidos, entre otros, por la doctrina brasileña, a la categoría de «derechos» de tercera generación, categoría ésta elaborada por KARELVASAK ${ }^{47}$ que se asienta sobre la solidaridad de las relaciones humanas ${ }^{48}$.

44 Es el caso, entre otros, de GutiéRrez de Cabiedes e Hidalgo de Caviedes, P., La tutela jurisdiccional..., cit., pp. 96 a 99; MONTERO AROCA, J., De la legitimación..., cit., p. 410; y DE LUCCHI LÓPEZ-TAPIA, Y., La tutela jurisdiccional..., cit., p. 34.

${ }^{45} \mathrm{Vid}$. a este respecto el Código Modelo de Procesos Colectivos para Iberoamérica. Es esta cuestión destacada por BUJOSA VADELL, L. M., en su artículo «La posición del juez en el código modelo de procesos colectivos para Iberoamérica». Disponible en http://www.ambitojuridico.com.br/site/index.php?n_link=revista_artigos I eitura\&artigo id=281, el 4 de abril de 2014, quien considera perfectamente admisible hablar de "derechos colectivos" o "difusos" [...] pues nada impide que el concepto clásico de "derecho subjetivo" evolucione como lo ha hecho el de "interés legítimo" y pueda referirse a realidades sociales con relevancia colectiva 0 supraindividual»».

46 Ello puede deberse a la circunstancia de que en el derecho brasileño, tal y como advierte Morello, A. M., Stiglitz, G., Tutela procesal de..., cit., pp. 177 a 178, «no se aprecia como fértil la distinción entre el derecho subjetivo y el interés legítimo», señalando a renglón seguido que bajo la rúbrica del derecho subjetivo «conviven englobladas e indiscriminadamente diversas situaciones que, en el foco de otros sistemas, serían discernidas distintamemnte, sometidas a regímenes protectores diversos».

47 A este checoslovaco afincado en París ex Director de la División de Derechos Humanos y Paz de la UNESCO_ se debe la teoría de las tres generaciones de los derechos humanos, enunciada en 1979 en su conferencia para el Instituto Internacional de Derechos Humanos de Estrasburgo. Para su elaboración tomó como inspiración la bandera francesa y los ideales que ésta representa: la libertad, la igualdad y la fraternidad, sustituyendo esta última por la presencia del valor «solidaridad». La tesis de 


\subsubsection{Naturaleza pública, privada o tertiumgenus}

Entre los esfuerzos doctrinales tendentes a encontrar la ubicación sistemática de los intereses supraindividuales, se comprueba cómo con base en argumentos distanciados se ha defendido, por un lado, su reconducción a los intereses privados ${ }^{49}$, por otro, su equiparación con los intereses públicos o generales ${ }^{50} \mathrm{y}$, por último, su encuadre en un plano intermedio constitutivo de un tertium genus.

Esta última postura, iniciada por CESARINI SFORZA ${ }^{51}$ al referirse a ellos como «más que privados y menos que públicos», es la que ha gozado de mayor aceptación en el seno de la doctrina española. A este respecto, entre los autores que se han dedicado a la materia destaca GUTIÉRREZ DE CABIEDES, quien atribuyendo una dimensión social a los intereses supraindividuales ${ }^{52}$, ha concluido que su mejor encuadre pasaría por situarles a medio camino entre los intereses estrictamente individuales y el propio interés público.

Por nuestra parte, si bien nos mostramos conformes con esta última corriente, disentimos del criterio seguido por el autor citado supra a la

KARELVASEK refleja el orden temporal sucesivo del reconocimiento internacional de los derechos humanos a nivel estatal, identificando tres generaciones que van de lo individualista a lo solidario. Vid. VASEK, K., Las dimensiones internacionales de los derechos humanos, Serval, Barcelona, 1984.

48 Pellegrini Grinover, A., «Hacia un sistema iberoamericano de tutela de intereses transindividuales», en Gidi, A., FerRer MAC-Gregor, E. (Coords.), La tutela de los derechos difusos colectivos e individuales homogéneos. Hacia un código modelo para Iberoamérica, Porrúa, México, 2003, pp. 31 a 32; CABReRA ACEVedo, L., «La tutela de los intereses colectivos o difusos». Disponible en: http: //biblio.juridicas.unam.mx/libros/2/592/14.pdf. Consultado el 21 de abril de 2015; AgUiRReZABAL GrünSTEIN, A., «Algunas precisiones en...», cit., pp. 69 y ss.

${ }^{49}$ Es el caso de SANTORO PASARelli, F., Nozioni di diritto..., cit., p. 21, que sostiene que el interés colectivo -que vendría a identificarse con el supraindividual-, aun siendo distinto del individual es, de por sí, un interés privado y no público.

50 SinAGRA, L., «Interventi», en VV. AA., Strumenti per la tutela degliinteressidellacollettività, MaggioliEditore, Rimini, 1981, p. 168, cuando sostiene que los intereses que se han querido llamar difusos -equiparables a los intereses supraindividuales- no son otra cosa que el interés público o general.

${ }^{51}$ Cesarini Sforza, W.,Il diritto dei privati, Giuffrè, Milano, 1963, p. 104.

52 GutiéRrez de Cabiedes e Hidalgo de Caviedes, P., La tutela jurisdiccional..., cit. pp. 86 a 87. Esta dimensión social ya les había sido atribuida con anterioridad por ALMAGRo NOSETE, J., Constitución y proceso, cit., p. 184, quien, de hecho, se refiere indistintamente a los intereses difusos y colectivos como «sociales». También han situado al interés supraindividual a medio camino entre el público y el privado: GonzÁLEZ CANO, M. I. , La tutela colectiva..., cit., p. 31; MONTERO AROCA, J., De la legitimación ..., cit., p. 411; DE LUCCHI LóPEZ-TAPIA, La tutela jurisdiccional..., cit., p. 35;GRANDE SeARA, P., «Capacidad y legitimación en los procesos para la tutela de los derechos e intereses de los consumidores y usuarios», en GonZÁlez PILLADO, E. (Coord.), Resolución de conflictos en materia de consumo: proceso y arbitraje, Tecnos, Madrid, 2010, p. 51;y BACHMAIER WINTER, L., «La tutela de los derechos e intereses colectivos de consumidores y usuarios en el proceso civil español», p. 7. 
hora de desligar el interés público del social o supraindividual ${ }^{53}$. De conformidad con su tesis, el distanciamiento entre ambos tipos de intereses radicaría en la vertiente personal o posibilidad de fragmentación que se da en el interés social y no en el público, y que a la postre justificaría una tutela diferenciada a instancia de sus titulares. En nuestra opinión, este último y el interés social únicamente se distanciarían en el plano de su tutela jurisdiccional, de modo que los intereses supraindividuales son sociales en tanto el Estado no asume directamente su protección.

La circunstancia de que el Ministerio Fiscal tenga reconocida legitimación para procurar su protección no implica que éstos sean intereses públicos, ya que entre las funciones que a la Fiscalía se encomiendan no se encuentra únicamente la defensa del interés público o general, sino también la protección del interés social. Esta conclusión se encuentra avalada por dos circunstancias: la primera, que la intervención de la Fiscalía en los procesos para la defensa de los intereses supraindividuales no es preceptiva, como sí lo es cuando los intereses en juego son públicos; y la segunda, que en los procesos en defensa de los intereses de incidencia social de los consumidores no se ha invertido el principio dispositivo al de oficialidad, como sí se ha hecho en los procesos civiles en los que se tutelen intereses públicos o generales -como sucedería, por ejemplo, en los procesos sobre el estado civil de la personas o en los procesos matrimoniales en los que intervienen menores- ${ }^{54}$.

Con todo, convenimos con VIGORITI, en que esta discusión es irrelevante en la práctica, por cuanto la naturaleza de los intereses puede variar con el tiempo, de modo que la resolución del problema de su naturaleza, lejos de circunscribirse a su subsunción como públicos, privados o sociales pasaría por atender a una serie de circunstancias contingentes en un momento y en un lugar determinado ${ }^{55}$.

53 Gutiérrez de Cabiedes e Hidalgo de Caviedes, P., La tutela jurisdiccional..., cit., pp. 86 a 87, atribuye una dimensión social al interés supraindividual, si bien se afana en distinguir el interés público del difuso, por entender que ésta es la clase de interés supraindividual más próximo al interés público. A este respecto debe tenerse presente que el autor distingue como subespecies del derecho supraindividual al interés difuso y al interés colectivo, entendiendo por el primero a aquel cuyos titulares se encuentran indeterminados o son difícilmente determinables y por los segundos a aquellos cuyos titulares se encuentran determinados o son fácilmente determinables. De ahí que -con base en la indeterminación de los afectados que se daría en ambos casos- advierta la mayor vinculación de los intereses difusos con el interés general y se refiera únicamente a éstos y no a los intereses supraindividuales en su conjunto. A su juicio «del interés difuso emana el reconocimiento de situaciones subjetivas atribuibles a individuos $y$ organizaciones».

54 DE LUCCHI LÓPEZ-TAPIA, Y., La tutela jurisdiccional..., cit., p. 37, incide igualmente en la circunstancia de que si los intereses de grupo -término éste en el que la autora entiende incluidos a los intereses supraindividuales y a los intereses individuales homogéneoshubiesen sido considerados como públicos, el principio dispositivo rector del proceso debiera invertirse al de oficialidad.

55 VIGORITI, V., Interessicollettivi e..., cit., pp.34 a 35.Igual parecer es compartido por DonzelLi, R., L'azione di classe a tutela dei consumatori, Jovene editore, Napoli, 2011, p. 304 , al manifestar que «Sicuramente è erore logico-concettuale contrapporre gli interessi 


\subsection{INTERESES «COLECTIVOS》Y «DIFUSOS》}

Como adelantamos al analizar las dificultades terminológicas que rodean el estudio de los intereses de incidencia social de los consumidores, las expresiones «intereses colectivos», «intereses difusos» e «intereses supraindividuales» fueron utilizadas durante un tiempo como fungibles y recíprocamente indiferentes ${ }^{56}$, siendo tan sólo en un segundo momento cuando se elaboraron criterios y factores de identificación y diferenciación de los unos respecto de los otros ${ }^{57}$. En esta segunda etapa los intereses colectivos y difusos pasan a ser considerados como las dos especies que

individuali a quello pubblici, in quanto si contrapongono grandezze disomogenee. Il contrassegnare como publicco un certo interesse non diche nulla, difatti, sulla sua struttura formale, ma serve solo per evidenziare la natura doverosa dell'attività che deve esser svolta per il soddisfacimento del medesimo. $\dot{E}$ dunque questo un problema solamente giuridico e non lato sensu ontologico».

${ }^{56}$ CAPPELLETTI, M., «Appunti sulla tutela...», cit., p. 192, habla de intereses de carácter difuso, colectivo, indistintamente, por cuanto no pertenecen al individuo sino a la colectividad. En igual sentido PROTO PISANI, A., «Appunti preliminari per...», cit., p. 265, tras destacar que la expresión «interés colectivo» se presenta como altamente equívoca, difícilmente distinguible respecto de aquella de «interés difuso», se decanta por referirse a ambas como «intereses superindividuales»; SCOCA, F. G., «La tutela degli interessi collettivi nel processo ammistrativo», en VV. AA., Le azioni a tutela di interessi colletivi, Cedam, Padova, 1976, p. 43, estable ce que «'interesse -comune a piùsoggetti-si specifichi da interessediffuso in interessecollettivo»; CARPI, F., «Intervento», en CAPPLLETTI, M. (Dir.), La tutela degliinteressidiffusi del Dirittocomparato, con paticolareriguardoallaprotezionedell' ambiente e deiconsumatori, Giuffrè, Milano, 1976, pp. 544 y ss.; GutiÉRREZ DE CABIEDES E HidAlgo DE CAVIEDES, P.,La tutela jurisdiccional..., cit., p. 99, señala a estos efectos que, en ocasiones, se hace mención tan sólo a uno de estos términos $y$, en otras, se emplean ambos, de forma cumulativa o alternativa, y de modo indistinto o estableciéndose una diferenciación, con base, a su vez, en criterios nada homogéneos.

Costantino, G., «Brevi note sulla...», cit., pp. 224 y ss., en el intento de ofrecer una explicación del caos terminológico existente en torno al concepto de interés colectivo, explica que en la experiencia jurídica italiana, con el termino interés colectivo, se había hecho referencia a múltiples y variados fenómenos que nada tenían que ver los unos con los otros, siendo a partir de la publicación de L'ordinamento giuridico de SANTI ROMANO en el año 1918, que la expresión «interés colectivo» comienza a asumir el significado más técnico y preciso, identificable con todas aquellas situaciones de ventaja no referibles ni al Estado persona jurídica, ni al sujeto individual. DE VITA, A., «La tutela giurisdizionale degli interessi collettivi nella prospettiva del sistema francese. Aspetti principali del problema e specificationi in tema di protezione degli interesse del consummatori», en CAPPELLETTI, M. (Dir.), La tutela degli interessi diffusi del Diritto comparato, con paticolare riguardo alla protezione dell' ambiente e dei consumatori, Giuffrè, Milano, 1976, p. 350, establece a este respecto que «Tali concetti(los de interés colectivo y difuso) si entendono spesso con valore sinónimo, e indubbiamente si referiscono a situazioni per molti aspetti analoghe», si bien tras reconocer el uso de ambos conceptos como sinónimos, matiza su diferenciación.

${ }^{57}$ En marco de las concepciones monistas podría distinguirse, al tiempo, una doble orientación. $Y$ es que, mientras ciertos autores defienden la irrelevancia de la distinción entre intereses colectivos y difusos, otros, entre ellos TROCKER, N., «Interessi collettivi e diffusi», en Enc. giur., XVII, Roma 1989, p. 2, advierten que no siempre reviste nitidez «quali caratteri debba avere questo grupo e quali connotati il suo aspetto organizzativo perché l'interesse si spacifichi da interesse diffusso in interesse collettivo». 
alberga el género de los «intereses supraindividuales», siendo muy variadas las tesis elaboradas con el propósito de deslindarlos unos de los otros $^{58}$.

Una de las más destacadas es la del «portador» introducida por GIANNINI ${ }^{59}$. Este autor considera que el interés difuso se encuentra privado de un portador legítimo, siendo entonces sustancialmente «anónimo», mientras que los intereses colectivos son aquéllos «que tienen como portador (o centro de referencia) un ente exponencial de un grupo no ocasional» ${ }^{60}$. Al defender que son colectivos los intereses representados por un ente exponencial, puede sostenerse que este autor sigue propiamente el criterio organizativo que, de manera un tanto más laxa, será posteriormente acogido por VIGORITI. Este último, en el camino hacia la separación y concreción de ambos tipos de interés, establece que mientras que los intereses colectivos significan un cierto grado de organización, los intereses difusos se refieren a un estado más fluido de agregación de los intereses individuales ${ }^{61}$.

Siguiendo a los dos autores citados, AcOSTA ESTÉvEZ considera que mientras que el interés difuso es «el interés propio, jurídicamente reconocido, de un grupo social o colectividad indeterminada de sujetos, desprovista de una organización que los tome para sí enteramente y tenga capacidad para su defensa, cuya tutela jurisdiccional responde a eventuales iniciativas meramente individuales», el interés colectivo es aquél que pertenece a un conjunto de «personas situadas en un mismo nivel o plano, en relación a un determinado bien respecto del que tienen exigencias del mismo tipo» ${ }^{62}$.

Por su parte, más allá del factor organizativo en sus diversas variantes, resulta destacable el criterio de la vinculación jurídica introducido por

58 Cfr. FerRARA, R.,Commentario breve alle leggi sulla giustizia amministrativa, a cura di A. Romano, Padova, 2001, p. 367. En igual sentido CARRATA, A., «Profili processuali della tutela degli interessi colletivi e diffusi», en LANFRANCHI. L., (Dir.), La tutela giurisdizionale degli intneressi collettivi e diffusi, G. Giappichelli, Torino, 2003, p. 84. Un completo análisis de las diversas teorías que han sido seguidas en esta materia lo encontramos en DONZELLI, R., L'azione di classe..., cit., pp. 162 y ss.

59 La aparición de las teorías dualistas se debe, en cierta medida, a las reflexiones realizadas por GianNini en su «Intervento» con ocasión del Convenio de Pavia 1974. Vid.DonzeLLI, R., La tutela giurisdizionale..., cit., p. 136, pie 37.

${ }^{60}$ Giannini,M., «La tutela degli...», cit., pp. 23 y ss. pp. 351 y ss., que «il giorno in cui un interesse diffuso trovi un portatore, diventa o colletivo o publico, a seconda de comma avviene, in termini positivi, la vicenda», en el mismo sentido RECCHIA, «Considerazioni sulla tutela di interessi diffusi nella Constituzione», en La tutela degli interessi difussi nel diritto comparato, Giuffrè, Milano, 1976, pp. 38 a 39.

61 DE VITA, A., «La tutela giurisdizionale...», cit., p. 350; VIGORITI, V., Interessi collettivi e..., cit., p. 61 ; CARRATTA, A., ., «Profili processuali della...», cit., p. 94, se refería a los intereses difusos como «interessi correlati a formazioni sociali "allo stato fluido", a formazioni sociali "ancora in fase di presa di coscienza di sé». PARDOLESI, R., «Il problema degli...», cit., p. 244 y ss., establecía que «sono interesi collettivi quelli di cui si faccia carico un portatore di interessi collettivi».

${ }^{62}$ Acosta EstéVEZ, J. B., Tutela procesal de..., cit., pp. 41 a 46. 
Pelegrinni ${ }^{63}$. Según esta autora, los intereses propiamente difusos serían «aquellos que no fundándose en un vínculo jurídico, se basan en datos de hecho genéricos y contingentes, accidentales y mudables: como habitar en la misma región, consumir los mismos productos, vivir en determinadas circunstancias socioeconómicas, someterse a particulares empresas», mientras que los intereses propiamente comunes o colectivos serían «aquellos intereses comunes a una colectividad de personas y solamente a ellas, cuando existe un vínculo jurídico entre los integrantes del grupo: la sociedad mercantil, el condominio, la familia, los entes profesionales, el mismo sindicato, dan margen a que surjan intereses comunes nacidos en función de una relación base que une a los miembros de las respectivas comunidades y que, no confundiéndose con los intereses estrictamente individuales de cada sujeto permiten su identificación» ${ }^{64}$.

En nuestro ordenamiento, la posición mayoritaria es la mantenida por GUTIÉRREZ DE CABIEDES, el cual considera que entre los intereses colectivos y difusos no existe diferencia ontológica alguna, distinguiéndose ambos, únicamente, por el dato extrínseco del grado de agregación ${ }^{65}$, o lo que es lo mismo, en razón de la mayor o menor concreción de los miembros del grupo. Éste ha sido, además, el criterio utilizado por la LEC para diferenciar los intereses colectivos de los difusos. Sin embargo, como veremos seguidamente, la definición que proporciona la LEC de estas dos categoría de intereses en su artículo 11.2 y 3 se identifican, únicamente, con las dos especies que integran el género de los «intereses individuales homogéneos».

Por el contrario, cuando la LEC se refiere a los intereses supraindividuales como «intereses colectivos y difusos», en realidad no establece distinción

63 Pellegrini Grinover, A., «Acciones colectivas para la defensa del ambiente y de los consumidores (La Ley brasileña núm. 7347 de 24 de julio de 1985)», en Revista de Derecho Procesal, 1988,núm. 3, pp. 705 a 724.

64 El criterio de la vinculación jurídica ha sido también empleado por nuestra jurisprudencia, vid. entre otras la sentencia del Juzgado de Primera Instancia núm. 21 de Barcelona, de 17 de octubre de 2003, al decir que «Los intereses colectivos existen cuando se da una vinculación jurídica entre los miembros del grupo y un tercero; por ejemplo, los afectados por la falta de higiene en determinado centro de trabajo. Los intereses difusos se dan cuando existe un interés supraindividual sin que entre los individuos interesados exista vínculo jurídico alguno, ni entre ellos y un tercero, sino que el nexo de unión que les agrupó obedece a circunstancias fácticas y contingentes; por ejemplo: los afectados por un producto defectuoso». En igual sentido, entre otras, la SAP de Sevilla (Sección $5^{a}$ ) 33/2004, de 22 de enero, por cuanto establecía a propósito de la determinación de los afectados por el cierre de la cadena de academias de enseñanza de inglés «Opening» que: «En el caso de autos los afectados son personas que necesariamente han firmado contratos por escrito con alguna o algunas de las entidades demandadas, contratos que por tanto han debido quedar registrados por dichas entidades. La determinación exacta del colectivo puede lograrse mediante la solicitud a los administradores de las entidades demandadas de los listados de los contratos concertados en vigor a la fecha del cese de los cursos de inglés que se impartían, para lo cual está incluso expresamente previsto una diligencia preliminar en el apartado $6^{\circ}$ del art. 256.1 de la LECiv» (F. J. $3^{\circ}$ ).

${ }^{65}$ GutiéRRez de Cabiedes e Hidalgo de Caviedes, P., La tutela jurisdiccional..., cit., p. 109. 
alguna entre estas dos modalidades de intereses. De hecho, la LEC incurre en un error al denominarles de este modo, pues el carácter indivisible de los intereses supraindividuales impide que puedan ser clasificados en razón del grado de agregación de los afectados. La tutela de estos intereses será necesariamente conjunta, con independencia de que la comunidad social afectada se encuentre integrada por sujetos indeterminados o fácilmente determinables ${ }^{66}$. Si tomamos como ejemplo el de las pretensiones de cesación, por ser éstas las pretensiones prototípicas en defensa de los intereses supraindividuales de los consumidores, comprobamos que la determinación o indeterminación de los afectados en ningún caso influye en la tramitación del procedimiento, siendo completamente ajeno a tal circunstancia.

Por el contrario, el criterio distintivo que atiende al grado de determinación de los afectados por el hecho dañoso, y que a la postre justificaría la perfilación de especialidades procedimentales, adquiriría virtualidad a propósito de los intereses individuales homogéneos, haciéndose depender de tal circunstancia, entre otros factores: el elenco de legitimados para instar su tutela, el sistema de publicidad e intervención, así como la delimitación del contenido de la sentencia y su ejecución ${ }^{67}$.

Por tanto, en el ámbito específico que nos ocupa, cual es de la defensa de los intereses de los consumidores, consideramos que resulta desacertado subclasificar a los intereses supraindividuales en colectivos y difusos.

66 En tal sentido se pronuncia DeNTI, V., «Interessi diffussi», en Novissimo Digesto It., Appendice, IV, Torino, 1983, p. 307. Por su parte, parece no compartir este criterio la doctrina del TS, así se desprende, entre otras, de su sentencia 861/2010, de 29 diciembre, al disponer al respecto de la interposición de una acción de cesación (en defensa, por tanto, del interés supraindividual) que «la apreciación de que la acción del caso se refiere a intereses colectivos, y no difusos, no ofrece duda, no solo ya porque así lo han considerado las propias partes, sino singularmente porque la nota distintiva de la "determinabilidad" resulta de que la cláusula discutida hace referencia a contratos de préstamo a interés variable celebrados por la entidad bancaria demandada, y produce perplejidad que la misma, mediante su sistema informático, no pudiera determinar plenamente los afectados. Y por otro lado, carece de consistencia alguna la pretensión de la recurrente de que se califique la acción como "difusa" por el hecho de tratarse de una acción de cesación, pues por mucho que pueda trascender -indirectamente- al mercado, lo cierto es que los consumidores o usuarios interesados son fácilmente determinables» (F. J. $2^{\circ}$ ).

67 Defiende lo contrario Gutiérrez de Cabiedes e Hidalgo de Caviedes, P.,La tutela jurisdiccional..., cit., pp. 99 y ss., pues si bien considera que los derechos supraindividuales admiten dicha desescalada, adquiriendo la forma, ora de intereses colectivos, ora de difusos, en función del dato extrínseco de agregación, aduce la imposibilidad de que respecto de los intereses individuales homogéneos se realice tal clasificación ulterior. Por su parte, GonzÁLEZ CANO, M. I., La tutela colectiva..., cit., pp. 23 y ss.; también en «El interés colectivo en materia de consumo: tipología, capacidad y legitimación», en ARIZA ColmenAREJO, M. J., Protección de los consumidores e inversores, arbitraje y proceso, Reus, Madrid, 2009, pp. 83 y 84, considera que tanto los intereses supraindividuales como los intereses individuales homogéneos pueden ser, a su vez, colectivos o difusos, en función de la mayor o menor determinabilidad de los afectados. 


\section{LOS INTERESES INDIVIDUALES HOMOGÉNEOS}

Los intereses individuales homogéneos son intereses esencialmente divisibles que, en atención a su origen común y a una serie de características que serán posteriormente analizadas, pueden ser tutelados procesalmente a través de las acciones colectivas ${ }^{68}$. Al tratarse de derechos subjetivos individuales, su titularidad recae sobre cada uno de los sujetos afectados por el hecho dañoso controvertido.

La necesidad de ofrecer a esta tipología de intereses la posibilidad de ser tutelados procesalmente de modo conjunto -que no acumulado- fue advertida por primera vez en un sistema de civil law, en el Código de Defensa del Consumidor brasileño de $1990^{69}$, en el que se hizo mención expresa a esta nueva categoría de derechos o intereses y se dio paso a las acciones colectivas reparadoras de los perjuicios individualmente padecidos, correspondiéndose éstas con las class actions for damages del Derecho norteamericano ${ }^{70}$.

En España, los intereses individuales homogéneos comenzaron a ser objeto de estudio desligado de los intereses supraindividuales, fundamentalmente, tras la aprobación de la LEC 1/2000. Como tuvimos ocasión de avanzar anteriormente, el término que ha sido mayormente acogido por la doctrina para calificar esta categoría de intereses es la de «intereses individuales homogéneos», aunque también se encuentra extendido el uso de la expresión «intereses pluiindividuales». Con todo, la terminología empleada por los autores no encuentra su reflejo en la LEC del 2000, que se refiere a ellos como «intereses colectivos y difusos» (arts. 11.2 y $3,15.2$ y 3 LEC, entre otros).

\subsection{NATURALEZA JURÍDICA}

En relación a la naturaleza de los intereses individuales homogéneos pueden distinguirse dos posiciones doctrinales: una minoritaria, que entiende que estos intereses constituyen una categoría sustantiva

\footnotetext{
68 Vid.Giannini, L. J., «La tutela colectiva...», cit., p. 7.

69 El Código de Defensa del Consumidor de Brasil define en su art. 81, junto con los intereses colectivos y difusos, a los intereses individuales homogéneos, como $I$ interesses ou direitos difusos, assim entendidos, para efeitos deste código, os transindividuais, de natureza indivisível, de que sejam titulares pessoas indeterminadas e ligadas por circunstâncias de fato; II - intereses ou direitos coletivos, assim entendidos, para efeitos deste código, os transindividuais, de natureza indivisível de que seja titular grupo, categoría ou classe de pessoas ligadas entre si ou com a parte contrária por uma relação jurídica base; III - intereses ou direitos individuais homogêneos, assim entendidos os decorrentes de origem comum». Disponible en: http://www.planalto.gov.br/ccivil_03/leis/l8078.htm. Consultado por última vez el 7 de mayo de 2016. En la misma línea que el Código de Defensa del Consumidor de Brasil, el Código modelo de procesos colectivos para Iberoamérica los define en el párr. $2^{\circ}$ art. 1 como «el conjunto de derechos subjetivos individuales, provenientes de origen común, de que sean titulares los miembros de un grupo, categoría o clase».

70 Las class actions for damages o damages class actions se encuentran reguladas en la subdivisión (b) (3) de la Rule 23 de las Federal Rules of Civil Procedure.
} 
autónoma $^{71}$, y una mayoritaria a la que nos sumamos, que considera que integran una categoría puramente procesal. En este último sentido se pronuncia GIDI al disponer expresamente que «Tal categoría de derechos representa una ficción [...] con la única y exclusiva finalidad de facilitar la protección colectiva (molecular) de los derechos individuales con dimensión colectiva (en masa)» 72 .

Los intereses 0 derechos individuales se transforman en «intereses individuales homogéneos» cuando se entabla una acción colectiva en defensa de los intereses de «todos» los afectados por el hecho dañoso controvertido. Por tanto, pueden ser considerados como una suma de derechos subjetivos individuales ${ }^{73}$, que en el proceso colectivo se sustancian como una unidad ${ }^{74}$. La contemplación unitaria de los derechos individuales concurrentes únicamente es posible tras la comisión de un hecho dañoso, de ahí que no quepa una tutela preventiva de los intereses individuales homogéneos, como sí cabe en relación a los intereses supraindividuales ${ }^{75}$.

Como tuvimos ocasión de avanzar anteriormente, en contraposición a los intereses supraindividuales, los intereses individuales homogéneos vienen referidos a bienes jurídicos divisibles, o lo que es lo mismo, bienes cuya lesión es susceptible de producir perjuicios individualizables, por lo que

71 Entre ellos podemos destacar la posición de LORENZETTI, R. L.,Justicia colectiva, Rubinzal-Culzoni, Santa Fe, 2004, p. 22.

72 Gidi, A., «Derechos difusos, colectivos e individuales homogéneos», en La tutela de los derechos difusos, colectivos e individuales homogéneos. Hacia un código modelo para Iberamérica, Porrúa, México, 2003, p. 35. Comparte esta misma idea, entre otros, ZANETI JUNioR, H., «Derechos colectivos latu sensu: la definición conceptual de los derechos difusos, de los derechos colectivos strictu sensu y de los derechos individuales homogéneos», en GIDI, A.; FERRER MAC-GREGoR, E. (Coords.), La tutela de los derechos difusos, colectivos e individuales homogéneos. Hacia un código modelo para Iberoamérica, Porrúa, México, 2003, p. 48.

73 Ello no puede llevar a la identificación de éstos con la plasmación acumulada de los derechos subjetivos concurrentes -esto es, con la mera suma de todos ellos-, respecto de los que si bien hay un solo procedimiento, habrá tantos procesos como acciones hayan sido acumuladas. Los intereses individuales homogéneos se tutelan a través de la acción colectiva, lo que implica que se incoa un solo proceso, en el que el legitimado extraordinariamente actúa como «portavoz» o «representante» de la totalidad de los perjudicados por el hecho dañoso. Ello no impide, sin embargo, que puedan existir peticiones diferentes, en tanto en cuanto las consecuencias dañosas sean divergentes.

74 Así lo considera MonTERo ArocA, J.,De la legitimación..., cit., p. 409, al definirlos como «el conjunto de derechos subjetivos individuales provenientes de origen común, de que sean titulares los miembros de un grupo, categoría o clase».

Gimeno SendRA, J. V., «Condición de parte procesal legítima. Legitimación para la defensa de derechos $e$ intereses de consumidores y usuarios (arts. 10 a 11)», La Ley 12696/2010, p. 17; López Fragoso, T., en Gimeno SendRA, V. (Dir.), Proceso Civil Práctico, La Ley, 2005, p. 115.

75 Como indica ZANETI JUNIOR, H., «Derechos colectivos latu sensu: la definición conceptual de los derechos difusos, de los derechos colectivos strictu sensu y de los derechos individuales homogéneos», », en La tutela de los derechos difusos, colectivos e individuales homogéneos. Hacia un código modelo para Iberoamérica, Porrúa, México, 2003 , p. 48, estos derechos nacen de una lesión, por lo que la relación jurídica entre las partes es post-factum. 
cada uno de los miembros del grupo afectado -en tanto titulares de los derechos subjetivos lesionados- podría procurar de manera individual su defensa en juicio, y también podrían hacerlo de modo acumulado. Sin embargo, la incidencia social del daño justifica que, en determinados casos, la tutela conjunta se erija en el medio más eficaz para garantizar su efectiva protección ${ }^{76}$.

Pongamos por caso que una empresa distribuye una partida de alimentos en mal estado. Cada uno de los afectados por la adquisición o consumo del producto tendrá reconocida -pues en caso contrario se vulneraría el derecho a la tutela judicial efectiva (art. 24 CE)- su legitimación en orden a iniciar un proceso individual por esta causa. A estos efectos, el propio artículo 11.1 de la LEC al regular la legitimación para la defensa de los consumidores y usuarios advierte de dicha facultad, pues dispone que el reconocimiento de legitimación en beneficio de las asociaciones de consumidores ha de entenderse «Sin perjuicio de la legitimación individual de los perjudicados» 77 .

Ello no obstante, comoquiera que la lesión de los derechos subjetivos de cada uno de los afectados comparte un mismo origen con otra pluralidad de afectados -en el caso expuesto, la distribución de la partida de alimentos en malas condiciones-, el conjunto de derechos subjetivos lesionados podrá adquirir una dimensión grupal, que permitirá a la postre su defensa a través de una «acción colectiva» entablada por alguno de los sujetos legitimados al efecto. Es la relevancia social del daño padecido ${ }^{78}$, la naturaleza del bien jurídico lesionado, el carácter de la lesión, el que posibilita su consideración objetiva como causa de tutela diferenciada ${ }^{79}$.

\subsection{PRESUPUESTOS PARA SU TUtela COLECTIVA}

La necesidad de proporcionar una respuesta unitaria en los supuestos de daños masivos, no viene impuesta por la naturaleza indivisible de lo que sea objeto del debate, ya que los intereses en juego vienen referidos a bienes esencialmente divisibles ${ }^{80}$. En estos casos, la canalización de la

${ }_{77}^{7}$ Cfr. Montero Aroca, J.,De la legitimación..., cit., p. 409.

77 Otro ejemplo ilustrativo a este respecto sería el de la distribución por parte de Volkswagen de automóviles cuyos motores habían sido trucados -que incorporaban un software capaz de reconocer que el coche era sometido a un control de contaminación, para a continuación activar una serie de medidas para que el nivel de emisiones se mantuviese dentro de los límites legales-. La suma de los intereses privativos de cada uno de los propietarios de vehículos trucados podrían justificar la interposición de una acción colectiva en defensa de los intereses individuales homogéneos.

78 A este respecto, el Código Modelo de Procesos Colectivos para Iberoamérica ha expresamente previsto por medio de su art. 2, núm. II, que en orden a la admisión de la demanda, es necesario, además de la adecuada representatividad del legitimado, la «relevancia social de la tutela colectiva, caracterizada por la naturaleza del bien jurídico, por las características de la lesión o por el elevado número de personas afectadas».

79 Montero Aroca, J., De la legitimación..., cit., pp. 408 y ss.

${ }^{80}$ De ahí que hayan sido considerados por BARBOSA MOREIRA, A., A tutela jurisdiccional dos intereses colectivos ou difusos, Temas de Direito Processual, Tercera serie, 193, 1984, p. 20, como «accidentalmente colectivos», a diferencia de los intereses supraindividuales (colectivos o difusos), de los que dice son intereses «esencialmente colectivos». 
controversia por medio de la acción colectiva viene justificada por la comunidad de intereses que se superpone al conjunto de los derechos subjetivos concurrentes, como consecuencia de su «origen común», su «homogeneidad» y el «elevado número de afectados» ${ }^{81}$. Estos tres criterios son, por tanto, los que deberán ser observados para determinar si la acción colectiva puede erigirse en el mejor instrumento en orden a obtener la tutela de los intereses lesionados.

A pesar de que aparentemente los dos primeros requisitos pudieran ser reconducidos a uno sólo -al entender que la homogeneidad trae causa del origen común ${ }^{82}$-, lo cierto es que tal y como ha señalado PELLEGRINI, el origen común puede ser insuficiente para caracterizar la homogeneidad ${ }^{83}$. Se analizará a continuación qué ha de entenderse por origen común y homogeneidad a los efectos de que los intereses individuales homogéneos puedan sustanciarse procesalmente a través de los cauces de la acción colectiva.

La expresión «origen común» viene a sustituir a la más precisa «cuestión común de hecho o de derecho», por lo que para analizar si se cumple este presupuesto es necesario evaluar si las acciones individuales que en su caso llegaran a interponerse en defensa de los derechos individuales concurrentes tienen una misma causa de pedir. Ahora bien, a los efectos de entender que los intereses concurrentes comparten un mismo origen no es necesario que exista un único hecho dañoso del que se deriven la totalidad de intereses afectados, de modo que el hecho del que trae causa la afección puede encontrarse disperso en el tiempo y en el espacio ${ }^{84}$.

81 BeRizonce, R. O., GiAnNini, L. J., «La acción colectiva reparadora de los daños individualmente sufridos en el anteproyecto iberoamericano de procesos colectivos», en Gidi, A., FerRer MAC-GRegor, E., (Coords.), La tutela de los derechos difusos, colectivos e individuales homogéneos. Hacia un código modelo para Iberamérica, Porrúa, México, 2003, p. 64.

82 Así lo ha entendido GIDI, A., «Derechos difusos, colectivos...», cit., pp. 36 a 37, al sostener que «la homogeneidad depende exclusivamente del origen común de los derechos, ellos no precisan ser iguales en su cualidad o cantidad. Asimismo, de la misma forma que el quantum de cada perjuicio es algo peculiar e irrelevante para caracterización de la homogeneidad de tales derechos, estos perjuicios sufridos pueden ser de diversas especies (patrimoniales, morales, etc.) sin comprometiendo de la referida homogeneidad. Al final "lo homogéneo" no se refiere a identidad o igualdad matemáticas entre los derechos individuales homogéneos juzgados en la sentencia colectiva».

83 Vid. Pellegrini Grinover, A., «La difessa degli...», cit., pp. 155 a 166, esta autora incide en la necesidad de que las cuestiones comunes a todos los afectados sean superiores a las cuestiones diferenciadas. Éste sería el mismo criterio asumido por el sistema norteamericano de las class actions, en el que se considera necesario en orden a la obtención de la certificación de una acción de tal clase, no sólo la Superiority-que sería el requisito al que estamos aludiendo-, sino también que la acción colectiva constituya en el caso concreto la mejor de las tutelas en orden a la obtención del resarcimiento de los sujetos implicados.

84 Así lo considera, entre otros, GIDI, A., «Class action and...», cit., p. 912. En igual sentido WATANABE, K., «Acciones colectivas: cuidados necesarios para la correcta fijación del objeto litigioso del proceso», en La tutela de los derechos difusos, colectivos e individuales homogéneos. Hacia un código modelo para Iberoamérica, Porrúa, México, 2003 , p. 9, incide en la circunstancia de que «la unidad factual y temporal no es su 
Una vez constatado el origen común habrá que evaluar si concurre el presupuesto de la homogeneidad, o lo que es lo mismo, si las situaciones que comparten un mismo origen son sustancialmente idénticas, existiendo entre ellas, de ser el caso, únicamente peculiaridades irrelevantes desde el punto de vista jurídico. $Y$ es que si existen grandes diferencias, el recurso al instrumento colectivo no será posible, pues no podrá resolverse la controversia mediante una decisión única ${ }^{85}$.

La conexidad que ha de concurrir para que pueda ser entablada la acción colectiva justificaría la canalización de la controversia mediante el litisconsorcio entre los miembros del grupo en una acción individual. Sin embargo, para que proceda el recurso colectivo es preciso que la acumulación de acciones no resulte viable como consecuencia del número de afectados, pues el instrumento colectivo debe ser concebido como un mecanismo subsidiario.

Una vez delimitados los presupuestos que han de concurrir para que los intereses individuales nacidos de daños masivos puedan ser tutelados mediante las acciones colectivas, cabe incidir en la necesidad de articular, siguiendo la estela de la generalidad de los ordenamientos que han regulado las acciones colectivas, una primera fase de admisión de la demanda o de «certificación» de la acción como colectiva. En ella, el juez debería evaluar si concurren: el origen común y la homogeneidad entre los intereses cuya tutela se pretende; la imposibilidad, por el número de afectados, de canalizar la controversia por los cauces ordinarios; $y$, además, la idoneidad del promotor de la causa para defender adecuadamente los intereses de los consumidores ${ }^{86}$.

presupuesto necesario. Las víctimas de una publicidad engañosa vehiculadas por varios órganos de prensa y en días repetidos, de un producto nocivo para la salud adquirido por varios consumidores durante un largo espacio de tiempo y en varias regiones, sufren daños causados por algunos hechos tan homogéneos, que los devuelven al "origen común" de todos ellos».

A este respecto señala Ferreres Comella, A., «Las acciones de clase ("class actions") en la Ley de Enjuiciamiento Civil», en Actualidad Jurídica Uría y Menéndez, núm. 11, 2005, p. 45, que el requisito de la commonallity en nuestro ordenamiento podría desprenderse de la referencia en el art. 11 LEC a «un solo hecho dañoso», de la que podría desprenderse: por un lado, que el origen del daño debe ser unívoco en relación con los distintos consumidores o usuarios afectados; $y$, por otro, que debe resultar innecesario proyectar la conducta o acción dañosa sobre todos y cada uno de los consumidores o usuarios representados, individualmente considerados.

85 Vid. Gidi, A., «Derechos difusos, colectivos...», cit., p. 35 a 97.

86 En el sistema norteamericano de las class actions, en la fase de certificación de la acción el juez deberá valorar, de conformidad con la Regla núm. 23 a) de las Federal Rules of Civil Procedure, que la clase es tan numerosa que el ejercicio acumulado de las diversas acciones devendría impracticable (numerosity). En segundo término, tendrá que analizar si existe identidad fáctica entre los miembros del grupo (commonality) y, por último, deberá corroborar que la acción entablada sea típica, esto es, que sea representativa de la que, en su caso, fuere entablada por cada uno de los miembros de la clase si hubieren promovido la acción (Typicality). Lo cierto es que este último parámetro se encuentra íntimamente ligado al primero, con lo que no resulta fácil su distinción. De hecho, en algunas ocasiones ha llegado a ser obviado o subsumido en la commonality o en la adecuacy of representation. Ello no obstante, en otros supuestos sí se hace mención separada de esta exigencia, distinguiéndola de las otras dos mencionadas, por 
Por otro lado, consideramos que sería conveniente que el juez tuviese la facultad, en esta primera fase de certificación de la acción como colectiva, al igual que acontece en el sistema norteamericano de las class actions, de crear subgrupos dentro de una misma clase. De este modo, ante la interposición de una acción colectiva en representación de los afectados por un mismo hecho dañoso, el juez podría crear subgrupos de afectados que respondiesen a un mismo perfil.

\subsection{INTERESES INDIVIDUALES HOMOGÉNEOS SUSCEPTIBLES DE TUTELA COLECTIVA}

Cuando una determinada conducta empresarial produce daños masivos, afectantes por consiguiente a una pluralidad de consumidores -en mayor o menor grado de determinación-, pueden distinguirse dos situaciones diversas en función de la entidad del daño que se les haya irrogado. Por un lado, podrían diferenciarse los intereses individuales homogéneos resultantes de perjuicios económicos de escasa entidad -small claims- y, por otro, los nacidos de agravios de mayor trascendencia a los que corresponderían compensaciones más sustanciosas.

Ambos supuestos han de poder canalizarse a través de los cauces de la acción colectiva. En el primer caso, porque es el único mecanismo eficaz en orden a disuadir el recurso por parte de las empresas a estas prácticas, toda vez que su tutela individual no resulta eficiente, ni en términos estratégicos ni económicos ${ }^{87}$. En cuanto a los segundos, porque entre las

ejemplo, en el caso Dolgow v. Anderson, 43 F.R.D. 472- E.D.N.Y., 1968. A su vez, al margen de los requisitos explícitos contenidos en la referida norma, los tribunales han venido identificando otros presupuestos implícitos cuya concurrencia es igualmente exigida. Estos últimos serían, esencialmente, tres: a) que se trate de una clase definible, b) que el representante sea miembro de la clase y c) que se trate de una controversia viva que no encierre cuestiones irrelevantes. Sobre tales requisitos explícitos e implícitos vid. Klonoff, R. H., Bilich, E.K.M., Class actions and other multi-party litigation. Cases and materials, American Casebook Series, West Group, St. Paul, Minn, 2000, pp. 41 y ss. En un sentido similar, el Código Modelo Iberoamericano exige la observancia de dos presupuestos específicos para que la demanda sea certificada como colectiva. A su regulación se dedica el art. $2^{\circ}$, Par. $1^{\circ}$ : el predominio de las cuestiones comunes sobre las individuales y la utilidad de la tutela colectiva.

También en el ordenamiento italiano se ha articulado esta fase de certificación de la acción como colectiva (art. 140 bis, 6). En ella, el juzgador, además de analizar si concurren los presupuestos de la admisión de cualquier demanda, tendrá que observar que concurren una serie de circunstancias particulares: en primer lugar, que la demanda no es manifiestamente infundada; en segundo término, que existe entre los intereses concurrentes la identidad necesaria que justifica la interposición de la acción de clase; y, en tercer lugar, que el actor se encuentra en disposición de representar adecuadamente los intereses de los consumidores ausentes. Vid. Donzelli, R., L'azione di clase..., cit., pp. 100 y ss.

87 En la Exposición de Motivos del Proyecto de Ley francés en favor de los consumidores, depositado por $M$. Thierry Breton -entonces ministro de economía- el 8 de noviembre de 2006 en la Asamblea nacional, (núm. 3430- Assemblée nationale, XII législature), proponía la circunscripción de las acciones de grupo a la reparación de los perjuicios inferiores a la cantidad de dos mil euros. De igual modo, la confederación general de pequeños y medianos empresarios, así como Jacques Degrandi, M. -président du Tribunal de Grande Instance de Paris-, proponían la fijación del montante a cuatro mil 
grandes ventajas que reporta la tutela judicial colectiva, se encuentra la economía procesal y la evitación de los fallos judiciales contradictorios, cuestiones éstas que revierten en beneficio de toda la sociedad. La limitación del ámbito de aplicación de las acciones colectivas a los supuestos en los que el perjuicio que se haya irrogado a cada consumidor sea inferior a un importe determinado, no implicaría más que la anteposición de los intereses empresariales a los intereses de toda la sociedad, extremo éste que en ningún caso puede ser justificado.

A pesar de que en el seno de nuestro ordenamiento no se hayan distinguido estos dos fenómenos -dispensándose idéntico tratamiento al conjunto de intereses individuales homogéneos- lo cierto es que, hubiera resultado preferible prever particularidades procesales en función del carácter de los daños irrogados, por ejemplo, en lo que a la adopción del sistema de opt-out u opt-in atañe $e^{88}$.

Por lo que a los primeros concierne, éstos se caracterizan por su naturaleza «serial», por cuanto a su respecto no se aprecian, con carácter general, la incidencia de cuestiones personales en orden a la estimación de cada derecho a la restitución o al resarcimiento. Piénsese en el caso de que el ilícito provocase un perjuicio patrimonial de seis euros a cada consumidor como consecuencia del cobro indebido de una comisión bancaria. En este caso, a pesar de que, efectivamente, cada uno de los

euros. En la vigenteLey, sin embargo, en lugar de establecerse un límite de cantidad, se ha optado por excluir de las indemnizaciones de grupo los perjuicios corporales y morales, de modo tal que sólo los «préjudices patrimoniaux résultant des dommages matériels subis par les consommateurs», pueden ser objeto de una acción de grupo, salvo en el caso de que hayan sido padecidos «à l'occasion de la vente ou de la fourniture de services» 0 «lorsque ces préjudices résultent de pratiques anti-concurrentielles» (Article L. 423-1 du Code de la consommation).

En torno a la posibilidad de fijar una cuantía a partir de la cual no pueden ser ejercitadas acciones colectivas, se pronuncia TARUFFO, M., «La tutela collettiva...», cit., p. 17, manifestando su oposición, al decir expresamente que «Un'idea del genere si fonda su un ragionamento a dir poco paradossale: l'azione collettiva serve a rendere tutelabili diritti che altrimenti non troverebbero la via del processo, ma la si vuole escludere proprio nei casi in cui è certo che questi diritti rimarrebbero senza tutela alcuna se non potessero farsi valere in forma collettiva. Allora, perché inttrodurre limiti di valore "al basso" anche per le ordinarie azioni individuali? Basterebbe stabilire un limite abbastanza elevato per ridurre el contenzioso civile in misura sostanziali! Naturalmente un limite di questo genere sarebbe incostituzionale; ma allora come giustificarlo come condizione richiesta per utilizzare la sola forma di tutela che protrebbe essere veramente efficace per una pluralità di soggetti?».

88 Esta necesidad se advierte igualmente en el Dictamen del Comité Económico y Social Europeo sobre la Comunicación de la Comisión al Parlamento Europeo, al Consejo, al Comité Económico y Social Europeo y al Comité de las Regiones - «Hacia un marco horizontal europeo de recurso colectivo», COM (2013) 401 final2014/C 170/11, en cuyo punto 1.6 se señala que, si bien coincide con la Comisión Europea en que debe reconocerse el derecho de las personas individuales a sumarse a acciones colectivas mediante procedimientos que den la posibilidad de participar en ellos de forma voluntaria (opt-in), observa también que hay otros casos en los que un procedimiento de desvinculación voluntaria (opt-out) presentaría ventajas: en particular, en el caso de que existan muchos perjudicados con perjuicios muy reducidos puede resultar conveniente ampliar la acción colectiva a todos los posibles perjudicados. 
consumidores «pueda», individualmente, defender su interés privativo, lo más común en la práctica -a la vista de que el perjuicio irrogado es sustancialmente menor a los gastos que la iniciación del proceso pueda ocasionar- será su inacción en orden a obtener la reintegración de aquello que se les adeuda ${ }^{89}$.

La situación descrita constituye una constante que se reproduce diariamente, siendo el consumidor víctima incesante de abusos empresariales imperceptibles que, evaluados de modo aislado resultan insignificantes pero, en su contemplación grupal, llegan a alcanzar grandes dimensiones.

De este modo, aunque sea advertida por el consumidor la circunstancia de que, por ejemplo, el producto que adquiere incluye tan solo el $95 \%$ de la cantidad indicada en el envase o el hecho de que le han sido cobrados dos euros de más en la factura de la luz, del teléfono, etc., este tipo de conductas empresariales ilícitas, en un porcentaje elevadísimo de los casos, no son perseguidas judicialmente. A la vista de su impunidad, tal situación se traduce en la reiteración o casi perpetuación de dichas prácticas, precisamente, por los desorbitados beneficios que obtienen las empresas al llevarlas a cabo ${ }^{90}$.

Dicho lo anterior, puede sostenerse que este tipo de hechos dañosos se erigen en el mejor campo de aplicación de las acciones colectivas, en buena medida por la fuerte influencia disuasoria que a su través se ejerce de cara a la reiteración de prácticas semejantes en el futuro ${ }^{91}$. La tutela colectiva de estas situaciones de ventaja coadyuvará a evitar la situación en la que el consumidor individual, en atención a la escasa cuantía patrimonial del daño sufrido y a las escasas probabilidades de éxito derivadas de su posición de desventaja frente al empresario, se ve abocado a no litigar ${ }^{92}$

89 CAppelletti, M., «Formazioni sociali e...», cit., pp. 363 y ss. Y 374, «l'individuo, "personalmente leso", legittimato ad agire esclusivamente per la riparazione del danno da lui subito, non è in grado di assicurare né a se estesso né alla collettività un'adeguata tutela contro violazione di interessi collettivi; non è in grado soprattutto, di monopolizzare tale tutela, la quale asssume caratteristiche del tutto particolarti e un'importanza sconosciuta finora nella storia del diritto». En igual sentido, TARUFFO, M., «La tutela collettiva...», cit., pp. 15 y ss.

90 Donzelli, R., L'azione di classe..., cit., p. 21 y 22., «L'elemento che più di ogni altro caratterizza queste controversie è la forte disparità di posizione tra parte professionale e singolo individuo; difatti, realizzatosi l'illecito, el vantaggio economico globale, ovvero aggregato, che l'autore de la condotta antigiuridica è in grado di conseguire è decisamente elevato, ma di contro il vantaggio economico che ciascun soggetto può ottenere da una eventuale vittoria è troppo esiguo per giustificare $i$ costi che dovrebbe sobbarcarsi per affrontare il giudizio».

91 DonzelLi, R., L'azione di classe..., cit., p. 22.

92 GiUssani, A., «Modello extraeuropei di tutela collettiva risarcitoria», en BeLLI, C. Le azioni collettive in Italia, Giuffrè, Milano, 2007, pp. 73 y 74, y también en GiussANI, A., «Enter the Damage Class Action in European Law: Heading Towards Justiceon a bus», Civil Justice Quarterly, vol. 28, issue 1, Thomson Reuters, 2009, utiliza una metáfora para explicar las acciones en defensa de intereses individuales homogéneos que resulta verdaderamente ilustradora. Así sostiene el autor que «L'azione collettiva riarcitoria a tutela di diritti individuali omogenei si può vedere coem un autobus, da introdurre in una 
En el extremo opuesto, podrían servir como ejemplo, los intereses individuales homogéneos surgidos de una partida de medicamentos en mal estado con graves consecuencias para la salud de los pacientes que los hubiera ingerido, como el conocido como «Caso de la Talidomida» ${ }^{93}$. Igualmente, podría ser traído el caso relativo a la intoxicación masiva por consumo de aceite desnaturalizado de colza no apto para el consumo humano. Supuesto este último que se erige en el precedente de las acciones colectivas en España, si bien en aquel supuesto la causa había sido sustanciada por los cauces del proceso penal.

En estos supuestos, los perjuicios individuales revisten entidad suficiente a fin de que los consumidores individualmente considerados asuman las riendas de un proceso en defensa de su derecho subjetivo. Sin embargo, la litigación colectiva, en determinados casos, aun no siendo imprescindible, «representa una opción más rápida y eficaz» ${ }^{94}$.

Por todo lo anterior, es preciso tener presente que aun cuando las dos realidades que acaban de ser comentadas son constitutivas de intereses individuales homogéneos, su canalización procesal por medio de los cauces de la acción colectiva debiera presentar especialidades diferenciadas ${ }^{95}$.

\section{LOS INTERESES DE INCIDENCIA SOCIAL DE LOS CONSUMIDORES EN LA LEC}

La LEC no alude expresamente a los intereses supraindividuales ni tampoco a los intereses individuales homogéneos. Ahora bien, aunque no los distinga prima facie, lo hace por medio del contenido de los preceptos que dedica a la regulación de las acciones colectivas, de tal suerte que es necesario ir matizando cuál es la naturaleza del interés al que ha querido

città -il sistema della giustizia civile- il cui trasporto pibblico è realizzato solo dai taxi [...] gli autobus sono più lenti dei taxi, e magari ne rendono anche più lenta la circolazione, ma l'effetto benefico complessivo sul sistema è evidente, perché diminuisce, a parità di persone trasportate, il numero di mezzi in strada (nella misura in cui alcuni potenziali utenti di diversi taxi posono raggrupparsi in un unico autobus), e inoltre accedono al trasporto pubbliccoanche coloro che non possono permettersi il costo del taxi (sicché aumenta la mobilità complessiva);l'azione collettiva risarcitoria a tutela di diritti individuali omogenei ambisce, analogamente, a raggruppare in un unico complesso procedimento un grande numero de controversie seriale, assicurando un trattamento meno "personalizzato" ma un significativo abbattimento del costo unitario, in modo da conseguire un complessivo incremento dell'attuazione del dirittossotanziale (quale risultato della migliore efficienza unitaria e dell'abbatimento dei costi di acceso)».

93 PARRA LUCÁN, M. A., «La responsabilidad civil por medicamentos y productos sanitarios a la luz del caso de la Talidomida», en Revista CESCO de Derecho del Consumo, núm. 8, 2013.

94 Gascón Inchausti, F., Tutela Judicial de..., cit., p. 144.

95 Tal diferenciación sí ha sido asumida, por el contrario, en otros ordenamientos como el alemán. Vid. a este respecto CAPONI, R., «Strumenti di tutela collettiva nel processo civile: I'esempio tedesco», en BELLI, C.,Le azioni collettive in Italia. Profili teorici ed aspetti applicativi, Giuffrè, 2007, pp. 55 y ss.; y también PlANCHAdELL GARGALLO, A.,Las "acciones colectivas"..., cit. , pp. 420 y ss. 
referirse en cada caso ${ }^{96}$. Empresa ésta que como comprobaremos a continuación, reviste más complejidad de la esperada. Y es que LEC $1 / 2000$ ha supuesto una oportunidad desperdiciada en orden a clarificar los conceptos a los que en las páginas precedentes nos hemos referido ${ }^{97}$.

En su artículo 11.1, la Ley procesal civil reconoce legitimación en beneficio de las asociaciones de consumidores y usuarios, no sólo en orden a procurar la defensa de los intereses de la propia asociación y de sus asociados -ambos individuales o privativos de sus titulares-, sino también para la defensa de los «intereses generales» de los consumidores y usuarios. En nuestra opinión, esta última referencia a los «intereses generales ${ }^{98}$ debe de entenderse hecha a lo que en estas líneas han sido denominados como «intereses supraindividuales» ${ }^{99}$. Con todo, no deben

96 La mayoría de la doctrina ha defendido, sin embargo, que los conceptos de intereses colectivos e intereses difusos sean interpretados en un sentido amplio, comprensivo tanto de los intereses supraindividuales como de los intereses individuales homogéneos GRANDE SEARA, P., «Capacidad y legitimación...», cit., pp. 53 y 54.

97 GRANDE SeARA, P., «Capacidad y legitimación...», cit., p. 52.

98 El contenido del primer apdo. del art. 11 LEC supone una reiteración, por cuanto el reconocimiento en beneficio de las asociaciones de consumidores de legitimación en orden a la defensa de sus propios intereses, de los intereses de sus asociados y de los intereses generales de los consumidores, ya se encontraba recogido en el art. 20. 1 LGDCU «Las Asociaciones de consumidores y usuarios se constituirán con arreglo a La Ley de Asociaciones y tendrán como finalidad la defensa de los intereses, incluyendo la información y educación de los consumidores y usuarios, bien sea con carácter general, bien en relación con productos o servicios determinados; podrán ser declaradas de utilidad pública, integrarse en agrupaciones y federaciones de idénticos fines, percibir ayudas y subvenciones, representar a sus asociados y ejercer las correspondientes acciones en defensa de los mismos, de la asociación o de los intereses generales de los consumidores y usuarios, y disfrutarán del beneficio de justicia gratuita en los casos a que se refiere el art. 2,2. Su organización y funcionamiento serán democráticos», sin que la entrada en vigor de la LEC supusiese la derogación de este precepto. Tal y como señala SAMANES ARA, C., Las partes en el proceso civil, La Ley, Madrid, 2000, pp. 86 a 87, la reiteración a la que aludimos probablemente obedeciese a un afán sistematizador del legislador fruto de la necesidad de regular en una norma procesal, una cuestión que reviste estrictamente tal carácter. A día de hoy, sería el art. 24.1 TRLGDCU el sucesor del entonces art. 20.1 LGDCU, rezando del modo que sigue:

«Las asociaciones de consumidores y usuarios constituidas conforme a lo previsto en este título y en la normativa autonómica que les resulte de aplicación, son las únicas legitimadas para actuar en nombre y representación de los intereses generales de los consumidores y usuarios.

Las asociaciones o cooperativas que no reúnan los requisitos exigidos en este título o en la normativa autonómica que les resulte de aplicación, sólo podrán representar los intereses de sus asociados o de la asociación, pero no los intereses generales, colectivos o difusos, de los consumidores».

99 Se han manifestado en igual sentido, entre otros: GutiérREZ DE CABIEDES, GuTIÉRREZ DE Cabiedes Hidalgo de Caviedes, P., en Cordón Moreno, F., ARmenta Deu, T., Muerza Esparza, J. J., TAPiA Fernández, I. (Coords.), Comentarios a la Ley de Enjuiciamiento Civil, Azanzadi, Cizur Menor (Navarra), 2001, pp. 215 a 218; DE LuCCHI LóPEZ-TAPIA, La tutela jurisdiccional..., cit., p. 58; GRANDE SEARA, P., «Capacidad y legitimación...», cit., p. 69. Ello no obstante, lo cierto es que en ocasiones, el propio legislador se refiere directamente a los intereses colectivos y difusos como las dos especies del interés general. 
entenderse estas dos expresiones como sinónimas, pues como ya sostuvimos al explicar la naturaleza de los intereses supraindividuales, éstos se encuentran a medio camino entre los intereses públicos o generales y los intereses privados, siendo considerados intereses sociales ${ }^{100}$.

A su vez, los apartados 2 y 3 del mismo precepto, distinguen respectivamente los «intereses colectivos» de los «intereses difusos», identificando a los primeros con los intereses cuyos titulares conforman un grupo de consumidores y usuarios determinados 0 fácilmente determinables $^{101}$, y los segundos con los intereses afectantes a una pluralidad de consumidores indeterminada o de difícil determinación. En estos dos apartados se incide únicamente en el grado extrínseco de agregación de los afectados, sin que se especifique en ningún momento la naturaleza de los intereses en juego, circunstancia ésta que nos lleva a cuestionarnos si los intereses colectivos y difusos (art. 11.2 y 3 LEC) son una especie de los «intereses generales» (art. 11.1 LEC) -tal y como han sido tradicionalmente concebidos por la doctrina- o, por el contrario, son distintos de estos últimos.

Pues bien, si reparamos en el contenido de los apartados 2 y 3 del artículo 11 LEC, comprobamos que las referencias a los «intereses colectivos»e

Así resulta de la lectura del art. 24.1 TRLGDCU, que establece que las únicas asociaciones legitimadas para la defensa de los «intereses generales de los consumidores y usuarios» son aquéllas constituidas de conformidad con las exigencias previstas en el Título II TRLGDCU y, a renglón seguido dispone que las asociaciones que no se constituyan del modo allí indicado o, en su caso, en la normativa autonómica que les resulte de aplicación, tan sólo podrán defender los derechos de sus asociados o de la asociación, pero no los intereses generales, colectivos o difusos, de los consumidores.

${ }^{100} \mathrm{Y}$ es que, si los intereses supraindividuales hubiesen sido elevados a la condición de generales o públicos debiera haberse configurado un proceso especial en el que el principio dispositivo hubiese sido sustituido por el de oficialidad. Probablemente la publificación de los intereses de incidencia social se producirá en los próximos tiempos. Ello no obstante, hasta que no suceda, no corresponderá aludir a los mismos como intereses generales.

${ }^{101}$ Dado que el legislador alude a una pretendida determinación de menor o mayor complejidad, sin establecer conforme a qué criterios ésta será medida, puede ser también de utilidad -aunque sólo para su determinación y no para su definición-, el criterio de la vinculación jurídica introducido por PELLEGRINI, pues generalmente, la vinculación jurídica viene de la mano de la determinación y, la ausencia de la anterior, de la indeterminación de los afectados. La expresión «fácilmente determinables» ha sido interpretada jurisprudencialmente no con base en la laboriosidad que pueda conllevar la tarea de identificación, sino en razón de la posibilidad efectiva de que tal identificación se lleve a término. Así se colige, por ejemplo, de la SAP de Sevilla (Sección $5^{a}$ ) 33/2004, de 22 de enero, con ocasión de la determinación de los afectados por el cierre de las academias de inglés «Opening»: «En el caso de autos los afectados son personas que necesariamente han firmado contratos por escrito con alguna o algunas de las entidades demandadas, contratos que por tanto han debido quedar registrados por dichas entidades. La determinación exacta del colectivo puede lograrse mediante la solicitud a los administradores de las entidades demandadas de los listados de los contratos concertados en vigor a la fecha del cese de los curos de inglés que se impartían, para lo cual está incluso expresamente previsto una diligencia preliminar en el apartado $6^{\circ}$ del art. 256.1 de la LECiv» (F. J. $3^{\circ}$ ). 
«intereses difusos» se acompañan del inciso «ser perjudicados por un hecho dañoso» ${ }^{102}$, con lo que la idea de la reparación de los daños efectivamente causados a los consumidores preside ambos apartados ${ }^{103}$. A la vista de lo anterior, debemos necesariamente concluir que las referencias hechas en estos dos apartados a los intereses colectivos y difusos vienen únicamente referidas a los intereses individuales homogéneos, por ser precisamente éstos los únicos que reclaman una tutela reparadora individualizada ${ }^{104}$. Como vimos en líneas previas, la tutela de los intereses supraindividuales exige en razón de su carácter

${ }^{102}$ Moreno Catena, V.; Guzmán Fluja, V. C.; Flores Prada, I., Informe sobre la situación de la protección procesal de los derechos de los consumidores y usuarios, Junta de Andalucía, Consejería de Trabajo e Industria, Sevilla, 1999, señalaban a propósito del PLEC como alternativa a la expresión «hecho dañoso» la de «daños y perjuicios derivados de la puesta en el mercado de bienes y servicios», por considerar que esta última comprendería, a diferencia de la primera, las diversas situaciones que pueden originar el litigio.

103 Esta referencia al «hecho dañoso» como causa justificativa de la especial legitimación conferida por el precepto en orden a defender los «intereses colectivos y difusos de los consumidores», no se contenía en la redacción del PLEC presentado ante el Congreso en 1998. El art. 9 (precedente del actual art. 11 LEC) se limita a disponer que «Las asociaciones de consumidores y usuarios y otras entidades legalmente constituidas para la defensa de los derechos e intereses de aquéllos, estarán legitimadas para defender dichos derechos e intereses conforme a las leyes que regulan su protección», de modo que ni tan siquiera aludía a la tipología de intereses que tales asociaciones estaban llamadas a proteger. Este precepto se limitaba a hacer una remisión a las leyes sectoriales que fuesen dictadas en la materia. Sería pues con ocasión de la enmienda 125 presentada por el partido socialista que la redacción del art. 9 pasaría a presentar un tenor mucho más próximo al actual, circunscribiendo de este modo el ámbito de aplicación del mismo al derecho de daños.

Muy probablemente, la reorientación del tenor del precepto se habría visto influenciado por el dramático suceso acaecido en los años 80 , el conocido como «síndrome tóxico» que había ocasionado cientos de muertes y miles de damnificados como consecuencia de la ingesta de aceite de colza desnaturalizado Aquel fatídico suceso contribuyó decisivamente en la política de protección de los consumidores y, desde luego, también ejerció cierta influencia en la redacción de los apartados que están siendo comentados, que ponen el acento en la tutela reparadora y no en la preventiva o inhibitoria, propia de los intereses supraindividuales. Esta es la opinión manifestada, entre otros, por LópEZ SÁNCHEZ, J., «La legitimación para el ejercicio de las acciones de cesación en defensa de los intereses colectivos de los consumidores y usuarios», en CARBONELL PORRAS, E. (Dir.), Intereses colectivos y legitimación activa, Aranzadi, Navarra, 2014, p. 217.

104 En un sentido contrario se han manifestado ANDRÉS CIURANA, B., «La sentencia dictada...», cit., p. 334, quien considera que los apdos. 2 y 3 del art. 11 vienen únicamente a concretar el contenido del art. 11.1 LEC de manera tal que los intereses colectivos y difusos serían las dos especies del interés supraindividual. MARTínEZ GARCÍA, E., «La legitimación para la defensa de los derechos e intereses de los consumidores y usuarios», en BARONA VILAR, S. (Coord.), Tutela de los Consumidores y usuarios en La Ley de Enjuiciamiento Civil, Tirant lo Blanch, Valencia, 2003, p. 123, equipara los intereses generales a los supraindividuales o sociales $y$, a renglón seguido, considera que estos intereses serían a su vez clasificables en generales colectivos y generales difusos, atendiendo, precisamente al criterio de la posible determinación de los miembros del grupo afectados. 
indivisible, un tratamiento unitario, no pudiendo concebirse a su respecto posiciones fragmentadas que justifiquen una reparación individualizada ${ }^{105}$. Con todo, la circunscripción del ámbito de aplicación del artículo 11.2 y 3 LEC a los procesos colectivos en defensa de intereses individuales homogéneos, pierde nitidez tras la transposición al ordenamiento español en el año 2002 de la Directiva 98/27/CE ${ }^{106}$. Y es que nuestro legislador, apartándose del propio criterio seguido por la Directiva, opta por referirse a los intereses que se encuentran en la base de la acción de cesación -acción prototípica en defensa de los intereses supraindividuales ${ }^{107}$ - con la expresión «intereses colectivos $y$ difusos», de modo que equipara, envolviendo bajo una misma nomenclatura, a intereses de naturaleza radicalmente distinta.

Desde nuestro punto de vista, como tuvimos ocasión de analizar anteriormente, la decisión del legislador en este punto resulta desafortunada, en un primer orden de cosas, porque en relación a los intereses supraindividuales no cabe hacer distinciones con base en el grado extrínseco de agregación de los afectados. Este factor subjetivo carece de relevancia en relación al interés supraindividual, desde el mismo instante en que no existe legitimación individual en orden a procurar su defensa ${ }^{108}$. La tutela de estos intereses será necesariamente conjunta y, ello, sin perjuicio de que la colectividad a la que pueda afectar esté integrada por sujetos determinados o fácilmente determinables, toda vez que la sentencia que ponga fin al proceso colectivo no requerirá una individualización posterior.

De este modo, debemos concluir que las referencias a los intereses colectivos y difusos realizadas en las leyes sectoriales así como en los preceptos de la LEC, en relación a las acciones de cesación (art. 11.4 y 5 LEC, entre otros), no pueden identificarse con los intereses colectivos y difusos de los apartados 2 y 3 del artículo 11 LEC. En esta circunstancia incide expresamente la Directiva 2009/22/CE del Parlamento Europeo y del Consejo, de 23 de abril de 2009, relativa a las acciones de cesación en materia de protección de los intereses de los consumidores. Por ello, hubiera resultado preferible que el legislador se hubiera referido a ellos como «intereses supraindividuales» ${ }^{109}$.

105 Ciertos autores, entre ellos, GutIÉRREZ DE CABIEDES, consideran que en estos dos apartados deben de entenderse incluidos los intereses supraindividuales, al considerar que el hecho dañoso puede ser interpretado en sentido amplio.

106 La transposición de la citada Directiva se lleva a cabo por medio de La Ley 39/2002, de 28 de octubre, de transposición al ordenamiento jurídico español de diversas directivas comunitarias en materia de protección de los intereses de los consumidores y usuarios.

107 En el estudio de la acción de cesación nos detendremos en el capítulo cuarto, al analizar el objeto de los procesos colectivos.

108 Cfr. Ariza Colmenarejo, M. J., La acción de..., cit., p. 23.

109 A la vista de lo expuesto en el texto, consideramos que constituye un error la previsión del art. 54.3 TRLGDCU merced a la cual «La legitimación para el ejercicio de la acción de cesación frente al resto de conductas de empresarios contrarias a la presente norma que lesionen intereses colectivos o intereses difusos de los consumidores y 
Llegados a este punto, la claridad exige que identifiquemos los preceptos de la LEC que, a nuestro juicio, se refieren a los intereses supraindividuales y a los intereses individuales homogéneos.

Pues bien, por lo que a los primeros concierne, su presencia se infiere, además del apartado 10 del artículo 11 -tal y como fue avanzado anteriormente-, de los artículos $11.4^{110}$ y 5 y 15.4 LEC $^{111}$, toda vez que los mismos aluden a las acciones de cesación ${ }^{112}$. A su vez, también la regla $2^{\mathrm{a}}$ del apartado $1^{\circ}$ del artículo 221 estaría dirigida a la protección de los intereses supraindividuales, al regular el contenido y efectos de aquellas sentencias en las que «como presupuesto de la condena o como pronunciamiento principal o único, se declarara ilícita o no conforme a la ley una determinada actividad o conducta»; y su apartado $2{ }^{\circ}$, al regular idénticos extremos de las sentencias «estimatorias de una acción de cesación en defensa de los intereses colectivos y de los intereses difusos». Por su parte, a los intereses individuales homogéneos vendrían referidos, por una lado, los apartados 2 y 3 del artículo 11 LEC -por los motivos sostenidos supra- por otro, los apartados 1,2 y 3 del artículo 15 LEC, pues este precepto regula la intervención de los «perjudicados por el hecho dañoso» a los efectos de que puedan asumir la defensa de su interés privativo en el proceso colectivo y, por último, del artículo 221

usuarios, se regirá por lo dispuesto en el artículo 11, apartados 2 y 3, de La Ley 1/2000, de 7 de enero, de Enjuiciamiento Civil», pues precisamente, la misma es fruto del equívoco que genera el uso indiscriminado de la expresión «intereses colectivos e intereses difusos», en relación a dos tipos de intereses completamente diferentes. De hecho, la introducción del apdo. 4 al art. 11 LEC -por mor de la Ley 39/2002, de transposición al ordenamiento español de la Directiva 98/97 en materia de acciones de cesación-, de conformidad con el cual: «Asimismo, el Ministerio Fiscal y las entidades habilitadas a las que se refiere el artículo $6.1 .8^{\circ}$ estarán legitimadas para el ejercicio de la acción de cesación para la defensa de los intereses colectivos y de los intereses difusos de los consumidores y usuarios», parecía partir de la premisa de que la legitimación conferida en beneficio de los sujetos contemplados en los apdos. 2 y 3 del art. 11 LEC no se hacía extensiva a las acciones de cesación, en defensa, por ende, de los intereses supraindividuales.

110 Este apartado reconoce legitimación a las entidades habilitadas conforme a la normativa comunitaria europea para el ejercicio de la acción de cesación.

${ }^{111}$ El art. 11.5 LEC no alude expresamente a las acciones de cesación, limitándose a establecer que «El Ministerio Fiscal estará legitimado para ejercitar cualquier acción en defensa de los intereses de los consumidores y usuarios», sin embargo, comoquiera que el MF puede entablar cualquier acción, también podrá entablar la acción de cesación o cualquier otra en defensa de los intereses supraindividuales de los consumidores. Recuérdese que este nuevo apdo. 5 ha venido a ampliar la legitimación del MF que, con carácter previo, únicamente tenía reconocida legitimación de acuerdo con el art. 11.4 LEC precisamente para el ejercicio de las acciones de cesación.

112 Este precepto ha sido recientemente modificado por la Ley 3/2014, pues en su antigua redacción (incorporada por la Ley 39/2002, de 28 de octubre, de transposición al ordenamiento jurídico español de diversas directivas comunitarias en materia de protección de los intereses de los consumidores y usuarios), aludía a la legitimación del Ministerio Fiscal para la interposición delas acciones de cesación. Como consecuencia de la redacción vigente, la legitimación del Ministerio Público -que se extiende a todo tipo de acciones colectivas y no sólo a la de cesación como se venía entendiendo- se incorpora en párrafo separado, concretamente el quinto (de nueva creación). 
LEC, cuya regla primera del apartado $1^{\circ}$ está dedicada a las pretensiones que implican una individualización «si se hubiere pretendido una condena dineraria, de hacer, no hacer, o dar cosa específica o genérica», tan sólo propia de los intereses de tal clase ${ }^{113}$.

\section{CONCLUSIONES}

En este trabajo se parte de la superación de la terminología empleada en la LEC 1/2000, de 7 de enero, cuando habla a lo largo de su articulado de intereses colectivos y difusos, pues esta expresión no abarca la totalidad de los intereses susceptibles de tutela colectiva.

La expresión intereses de «incidencia social de los consumidores», por la que nos hemos decantado para referirnos, de modo genérico, a todos los intereses susceptibles de ser tutelados mediante las llamadas acciones colectivas, es la que a nuestro juicio, refleja con mayor precisión la naturaleza de los intereses en juego: los intereses supraindividuales y los individuales homogéneos. Los intereses supraindividuales son intereses sociales en sentido estricto; mientras que los intereses individuales homogéneos, si bien en su génesis son intereses privativos, su lesión presenta cierta relevancia social -por el elevado número de afectados, las características de la lesión, etc.-, que es la que a la postre permite que puedan ser tutelados por medio de un cauce procesal conjunto.

Los intereses supraindividuales son intereses sociales que, al venir referidos a bienes jurídicos indivisibles, pertenecen a una comunidad social, y no de manera individual a cada uno de los miembros que la integran. Como consecuencia de su carácter indivisible deben ser tutelados, necesariamente, a través del cauce colectivo, de tal manera que el pleito que se inicie en su defensa repercutirá sobre toda la comunidad afectada.

La tutela de los intereses supraindividuales no variará en función de la posibilidad de determinación o no de los afectados.

Los intereses individuales homogéneos son una categoría procesal que engloba a un conjunto de derechos subjetivos individuales que comparten un mismo origen y presentan un contenido homogéneo. Al venir referidos a bienes jurídicos divisibles, cada uno de los miembros del grupo afectado podría ejercitar de manera individual la defensa de su derecho. Sin embargo, la incidencia social del daño justifica que, en determinados casos, la tutela conjunta se erija en el medio más eficaz para garantizar su efectiva protección.

La tutela de los intereses individuales homogéneos variará en función de la posibilidad de determinación o no de los afectados.

\section{BIBLIOGRAFÍA}

ACOSTA ESTÉVEZ, J. B., Tutela procesal de los consumidores, Bosch, Barcelona, 1995.

ALMAGRO NOSETE, J., Constitución y proceso, Bosch, Barcelona, 1984.

113 Grande SeARA, P., «Capacidad y legitimación...», cit., p. 53. 
ALPA, G., Responsabilità dell'impresa e tutela del consumatore, Milano, 1975.

ÁLVAREZ ALARCÓN, A., «La protección de los consumidores y usuarios: intereses individuales e intereses de grupo», en ALONSO-CUEVILLAS SAYROL, J., Instituciones del nuevo proceso civil. Comentarios sistemáticos a la Ley 1/2000, vol. 1, Barcelona, 2000.

ARIZA COLMENAREJO, M. J., La acción de cesación como medio para la protección de consumidores y usuarios, Aranzadi, Navara, 2012.

ARIZA COLMENAREJO, M. J., Protección de los consumidores e inversores, arbitraje y proceso, Reus, Madrid, 2009.

ARMENTA DEU, T., Acciones colectivas: Reconocimiento, cosa juzgada y ejecución, Marcial Pons, Madrid, 2013.

BARBOSA MOREIRA, A., A tutela jurisdiccional dos intereses colectivos ou difusos, Temas de Direito Processual, Tercera serie, 193, 1984.

BARBOSA MOREIRA, A., «A ação popular do direito brasileiro como instrumento de tutela jurisdiccional dos chamados "intereses difusos"», en Temas de DireitoProcessual, S.P., Saraiva, 1977.

BERIZONCE, R. O., GIANNINI, L. J., «La acción colectiva reparadora de los daños individualmente sufridos en el anteproyecto iberoamericano de procesos colectivos», en GIDI, A., FERRER MAC-GREGOR, E., (Coords.), La tutela de los derechos difusos, colectivos e individuales homogéneos. Hacia un código modelo para Iberamérica, Porrúa, México, 2003.

BONAUDI, E., La tutela degli interesi diffussi, Bocca, Torino, 1911.

BUJOSA VADELL, L. M., La protección jurisdiccional de los intereses de grupo, Bosch, Barcelona, 1995.

CAPPELLETI, M. «Appunti sulla tutela giurisdizionale di interessi collettivi o diffusi», en VV. AA., Le azioni a tutela di interessi colletivi, Cedam, Padova, 1976.

CARNELUTTI, F., Sistema de Derecho Procesal Civil, Uteha, Buenos Aires, 1944.

CARRATA, A., «Profili processuali della tutela degli interessi colletivi e diffusi», en Lanfranchi. L., (Dir.), La tutela giurisdizionale degli intneressi collettivi e diffusi, G. Giappichelli, Torino, 2003.

CARPI, F., L'efficacia ultra partes della sentenza civile, Milano, 1974.

CASTÁN TOBEÑAS, J., «El concepto de derecho subjetivo», en RDPriv, núm. 281, 1940.

CESARINI SFORZA, W., Gli interessi collettivi e la Constituzione, Diritto del Lavoro, 1964.

CESARINI SFORZA, W., Il diritto dei privati, Giuffrè, Milano.

CESARINI SFORZA, W., Lezioni di teoria generale del diritto I, Padova, 1931.

COSTANTINO, G., «Brevi note sulla tutela giurisdizionale degli interessi collettivi davanti al giudice civile», en Le azioni a tutela di interessi colletivi, Cedam, Padova, 1976.

DELGADO RODRÍGUEZ, A. F., «Intereses plurales: Análisis de su protección procesal en Estados Unidos como opción de desarrollo del 
$9.2^{\circ}$ C.E. y del art. $7.3^{\circ}$ L.O.P. J.», en Anales de la Facultad de Derecho, Universidad de la Laguna, núm. 16, 1999.

DE LUCCHI LÓPEZ-TAPIA, Y., La tutela jurisdiccional civil de consumidores y usuarios, Edisofer, Madrid, 2005.

DE VITA, A., «La tutela giurisdizionale degli interessi collettivi nella prospettiva del sistema francese. Aspetti principali del problema e specificationi in tema di protezione degli interesse del consummatori», en CAPPLLETTI, M. (Dir.), La tutela degli interessi diffusi del Diritto comparato, con paticolare riguardo alla protezione dell' ambiente e dei consumatori, Giuffrè, Milano, 1976.

D'ONOFRIO, F., «Prime reflessioni sul Diritto di acceso alla radiotelevisione» en $L a$ tutela degli interessi difussi nel diritto comparato, Giuffrè, Milano, 1976.

DONZELLI, R., La tutela giurisdizionale degli interessi collettivi, Jovene, Napoli, 2008.

FAIRÉN GUILLÉN, V., Estudios de Derecho Procesal, en Revista de Derecho Privado, Madrid, 1955.

FERRARA, R., Commentario breve alle leggi sulla giustizia amministrativa, a cura di A. Romano, Padova, 2001.

FERRERES COMELLA, A., «Las acciones de clase ("classactions") en la Ley de Enjuiciamiento Civil», en Actualidad Jurídica Uría y Menéndez, núm. $11,2005$.

GAMBARO, A., La tutela degli interessi diffusi nel diritto comparato, Milano, 1976.

GASCON INCHAUSTI, F., Tutela Judicial de los consumidores $y$ Transacciones colectivas, Thomson Civitas, Pamplona, 2010.

GIANNINI, L. J., «La tutela colectiva de derechos individuales homogéneos en la Argentina (Marchas y contramarchas del Proyecto de Código Civil y Comercial)», en Revista de Derecho Procesal, Rubinzal Culzoni, núm. 2013-1, «Proyecto de Código Civil y Comercial. Aspectos procesales».

GIDI, A., «Las acciones colectivas y la tutela de los derechos difusos, colectivos e individuales en Brasil. Un modelo para países de Derecho Civil», Doctrina Jurídica, núm. 151, UNAM, México, 2004.

GIDI, A., «Classaction and "amparo colectivo" in Brazil. The protection of diffuse, collective and homogeneous individual rights» (trad. de Lucio Cabrera Acevedo y Eduardo Ferrer Mac-Gregor), en Derecho Procesal Constitucional, vol. 3, Eduardo Ferrer Mac-Gregor, Porrúa, México, Suprema Corte de Justicia, Colegio de Secretarios, 2003.

GIDI, A., «Derechos difusos, colectivos e individuales homogéneos», en La tutela de los derechos difusos, colectivos e individuales homogéneos. Hacia un código modelo para Iberamérica, Porrúa, México, 2003.

GIMENO SENDRA, J. V., «Condición de parte procesal legítima. Legitimación para la defensa de derechos e intereses de consumidores y usuarios (arts. 10 a 11)», La Ley 12696/2010.

GIUSSANI, A., «Modello extra europei di tutela collettiva risarcitoria», en Belli, C., Le azioni collettive in Italia, Giuffrè, Milano, 2007.

GONZÁLEZ CANO, M. I., La tutela colectiva de consumidores y usuarios en el proceso civil, Tirant lo Blanch, Valencia, 2002. 
GRANDE SEARA, P., «Capacidad y legitimación en los procesos para la tutela de los derechos e intereses de los consumidores y usuarios», en GONZÁLEZ PILLADO, E. (Coord.), Resolución de conflictos en materia de consumo: proceso y arbitraje, Tecnos, Madrid, 2010.

GUASP DELGADO, J., Derecho, Gráficas Hergón, Madrid, 1971.

GUTIÉRREZ DE CABIEDES E HIDALGO DE CAVIEDES, P., La tutela jurisdiccional de los intereses supraindividuales: colectivos y difusos, Aranzadi, Navarra, 1999.

JAEGER, P. G, L'interesse sociale, Milano, 1964, p. 3; Jaeger, N.,Corso di diritto processuale civile, Milano, 1956.

LÓPEZ FRAGOSO, T., en GIMENO SENDRA, V., (Dir.), Proceso Civil Práctico, La Ley, 2005.

LORENZETTI, R. L., Justicia colectiva, Rubinzal-Culzoni, Santa Fe, 2004.

LOZANO-HIGUERO Y PINTO, M. L., La protección procesal de los intereses difusos. Intereses de los consumidores, ecológicos, urbanísticos, el acceso a la R.T.V., Madrid, 1983.

MARÍN LÓPEZ, J. J., en BERCOVITZ, R.; SALAS, J. (Coord.), Comentarios a La Ley General para la defensa de los Consumidores y Usuarios, Madrid, 1992.

MONTERO AROCA, J., De la legitimación en el proceso civil, Bosch, Barcelona, 2007.

PARDOLESI, R., «Il problema degli interessi collettivi e i problema dei giuristi», en VV. AA., Le azioni a tutela di interessi colletivi, Cedam, Padova, 1976.

PARRA LUCÁN, M. A., «La responsabilidad civil por medicamentos y productos sanitarios a la luz del caso de la Talidomida», en Revista CESCO de Derecho del Consumo, núm. 8, 2013.

PELLEGRINI GRINOVER, A., «Hacia un sistema iberoamericano de tutela de intereses transindividuales», en GIDI, A., FERRER MAC-GREGOR, E. (Coords.), La tutela de los derechos difusos colectivos e individuales homogéneos. Hacia un código modelo para Iberoamérica, Porrúa, México, 2003.

PELLEGRINI GRINOVER, A., «Acciones colectivas para la defensa del ambiente y de los consumidores (La Ley brasileña núm. 7347 de 24 de julio de 1985)», en Revista de Derecho Procesal, 1988, núm. 3.

PROTO PISANI, A., «Appunti preliminari per uno studio sulla tutela giurisdizionale degli interessi collettivi (o piu esattamente: superindividuali) innanzi al giudice civile ordinario», en VV. AA., Le azioni a tutela di interessi colletivi, Cedam, Padova, 1976.

ROCCO, A., «I concetti di bene e di interessi nel dirito penale e nella teoria generale del diritto», en Revista Italiana per le Scienze Giuridiche, 1910.

SANTORO PASSARELLI, F., Nozioni di diritto del lavoro, Napoli, 1995.

SILGUERO ESTAGNAN, J., La tutela jurisdiccional de los intereses colectivos a través de la legitimación de los grupos, Dykinson, Madrid, 2005. 
SCOCA, F. G., «La tutela degli interessi collettivi nel processo ammistrativo», en VV. AA., Le azioni a tutela di interessi colletivi, Cedam, Padova, 1976.

SINAGRA, L., «Interventi», en VV. AA., Strumenti per la tutela degli interessi della collettività, Maggioli Editore, Rimini, 1981.

SOLARI, G., Individualismo e dirittoprivato, Torino, 1911, reimpresión 1959.

TARUFFO, M., «La tutela collettiva: interessi in gioco ed esperienze a confronto», en BELLI, C., Le azioni collettive in Italia. Profili teorici ed aspetti applicativi, Giuffrè, Atti al convegno-Roma, 16 de febrero 2007.

TARUFFO, M., «I limiti soggettivi del giudicato e le «class actions»», en Rivista di Diritto Processuale, 1969.

VIGORITI, V., Interessi collettivi e proceso. La legitimazione ad agire, Giuffrè, Milano, 1979.

WATANABE, K., «Acciones colectivas: cuidados necesarios para la correcta fijación del objeto litigioso del proceso», en La tutela de los derechos difusos, colectivos e individuales homogéneos. Hacia un código modelo para Iberoamérica, Porrúa, México, 2003.

ZANETI JUNIOR, $\mathrm{H}_{\text {., }}$ «Derechos colectivos latu sensu: la definición conceptual de los derechos difusos, de los derechos colectivos strictu sensu y de los derechos individuales homogéneos», en GIDI, A.; FERRER MAC-GREGOR, E. (Coords.), La tutela de los derechos difusos, colectivos e individuales homogéneos. Hacia un código modelo para Iberoamérica, Porrúa, México, 2003.

ZANUTTIGH, L., «Interventi», en STANZANI, D.; FIORE, A. (Eds.), Strumenti per la tutela degli interessi della collettività, Maggioli Editore, Rimini, 1981. 